\title{
Cumulative Disadvantage: Examining RaCial AND EThNic DisParity in Prosecution AND Sentencing ${ }^{1}$
}

\begin{abstract}
Research on criminal case processing typically examines a single outcome from a particular decision-making point, making it difficult to draw reliable conclusions about the impact that factors such as defendants' race or ethnicity exert across successive stages of the justice system. Using a unique dataset from the New York County District Attorney's Office that tracks a large sample of diverse criminal cases, this study assesses racial and ethnic disparity for multiple discretionary points of prosecution and sentencing. Findings demonstrate that the effects of race and ethnicity vary by discretionary point and offense category. Black and Latino defendants were more likely to be detained, to receive a custodial plea offer and to be incarcerated, but they were also more likely to benefit from case dismissals. Blacks and Latinos received especially punitive outcomes for person offenses. The findings for Asian defendants were less consistent but in general suggest they were the least likely to be detained, to receive custodial offers, and to be incarcerated. These findings are discussed in the context of contemporary theoretical perspectives on racial bias and cumulative disadvantage in the justice system.
\end{abstract}

\footnotetext{
${ }^{1}$ Requests for additional information about this study should be directed to (self-citation omitted). This study was supported by grant (citation omitted) from the National Institute of Justice, Office of Justice Programs, U.S. Department of Justice. Points of view expressed in this report are those of the authors and do not necessarily represent the official position of the U.S. Department of Justice or the views of the district attorneys in participating jurisdictions.
} 


\section{Cumulative Disadvantage: Examining RACial AND ETHNic DisPaRity in Prosecution And Sentencing}

Politicians, policymakers, legal scholars, and social scientists have long debated the relationship between criminal justice decision making and racial and ethnic justice in society. Racial and ethnic minorities are overrepresented at all stages of the justice system, yet relatively little is known about the underlying sources of these disparities or the ways they are altered through the life-course of criminal cases. Research on racial and ethnic disparity typically has been limited to a single decision-making point, capturing only a snapshot of the more dynamic process that constitutes criminal punishment. This has long been recognized as a key limitation of research on racial justice. Early on, Hagan (1974: 379) called for studies that better capture "transit through the criminal justice system" especially as it operates "cumulatively to the disadvantage of minority group defendants." Nearly forty years later, Baumer (2013: 240) reiterated this concern, arguing that "it would be highly beneficial if the next generation of scholars delved deeper into the various ways that "race" matters "across multiple stages of the criminal justice process."

Investigating racial inequity across successive stages of the justice system is important for several reasons. To the extent that racial minorities are treated more punitively, cumulative disadvantages may emerge that are substantial and that go undetected in single-stage studies (Spohn, 2009). Alternatively, racial disparities that occur at one stage of the justice system may be partially or wholly offset by subsequent case processing decisions. Without examining multiple case outcomes, it is difficult to reliably assess the joint and cumulative effects of race and ethnicity on punishment. Moreover, improved estimates of racial and ethnic disparity are needed to better inform contemporary perceptions of racial injustice. Survey research demonstrates that minority respondents report lower levels of trust and confidence in the justice system; they also are more likely to believe that the system is racially biased (Hagan, Shedd, and Payne, 2005; Hagan and Albonetti, 1982). Perceived injustice is important because it fuels racial differences in assessments of the legitimacy of the criminal justice system, which can contribute to a variety of negative life outcomes, such as increased crime rates, worsening race relations, and ongoing social inequalities in other life domains (LaFree, 1998; Tyler, 2007). 
Each of the principal actors in the criminal justice system-law enforcement officials, prosecutors, and judges - is vested with key decision-making power that holds the potential to contribute to racial inequity in punishment. Data on arrests and prison statistics demonstrate consistent disproportionality in racial contact with the system. Blacks comprise 28 percent of people arrested (Federal Bureau of Investigation, 2011) and 38 percent of prison inmates (Carson and Sabol, 2012), despite being only 13 percent of the national population (U.S. Census Bureau, 2011). Similarly, Hispanics comprise 23 percent of prison inmates (Carson and Sabol, 2012) despite being only 17 percent of the general population (U.S. Census Bureau, 2011). However, little information exists on racial disparities in the case processing stages that precede imprisonment; this is especially true regarding racial differences in prosecutorial decision making and the subsequent effects of these differences on downstream punishment outcomes (Engen and Wright, 2006; Wright and Engen, 2006; for exceptions see, Schlesinger, 2007; Stolzenberg, D'Alessio and Eitle, 2013; Sutton, 2013 ).

To better understand the locus and magnitude of racial differences in punishment, it is useful to conceptualize the punishment process as a dynamic set of interrelated decision-making points (Baumer, 2013; Blumstein et al., 1983; Ulmer, 2012). The current study, which adopts this approach, contributes to existing research in several key ways. First, we use unique data from New York County (i.e., Manhattan) to estimate racial and ethnic disparity in multiple discretionary points, from case screening to sentencing, including seldomexamined prosecutorial outcomes. Second, we analyze a large sample of diverse crime types from a large urban jurisdiction. Third, we go beyond the traditional focus on blacks and, to a lesser extent Latinos, by incorporating Asians into estimates of racial disparity. Fourth, we include proxies for socioeconomic status and examine how these affect estimates of racial disparity. Fifth, we examine the prevalence of racial disparities for property, person and drug offenses separately. And finally, we contextualize the findings by drawing upon practitioner feedback provided throughout data collection, analysis, and interpretation of results. Before turning to the theory, analysis, and results, we review prior research on racial disparity in prosecution and sentencing and describe the current research context.

\section{Prior ReSearch on Racial and Ethnic Disparity in Criminal CaSe Processing}


Over the past several decades, criminologists, sociologists, and legal scholars have examined racial disparities in punishment, with a substantial research literature developing in the area (Spohn, 2000; Zatz, 2000). However, the majority of this work assesses the final sentencing decision (Crawford, Chiricos, and Kleck, 1998; Johnson, 2003; Kramer and Steffensmeier, 1993; Peterson and Hagan, 1984; Spohn, Gruhl, and Welch, 1981; Spohn and Holleran, 2006; Steen, Engen, and Gainey, 2005; Steffensmeier, Ulmer, and Kramer, 1998; Zatz, 1984). Collectively, this work suggests that although legally-relevant factors exert the strongest influence on punishment, significant disadvantages remain for black and Latino defendants net of legal considerations (Spohn, 2000; Mitchell, 2005; Zatz, 2000). In addition, there is evidence suggesting that the degree of racial disparity in sentencing is conditioned by other factors, such as the age, gender, and employment status of the defendant (Spohn, 2000; Spohn and Holleran, 2006; Steffensmeier, Ulmer, and Kramer, 1998), the type of conviction offense (Johnson and Betsinger, 2009; Mustard, 2001), or the surrounding social context of the court (Ulmer and Johnson, 2004; Wang and Mears, 2010).

Comparatively little research focuses on racial disparity in prosecution, despite the fact that prosecutors have broad and largely unregulated case processing authority (Forst, 2002), and very few studies examine the cumulative effects of race across multiple discretionary points (Albonetti, 1987; Baumer, 2013).Research on racial disparity in punitive decisions controlled by prosecutors has examined the initial decision to file charges (Albonetti, 1987; Baumer, Messner, and Felson, 2000; Beichner and Spohn, 2005; Frazier and Haney, 1996; Frederick and Stemen, 2012; Spears and Spohn, 1997; Spohn, Beichner, and Davis-Frenzel, 2001; Spohn and Holleran, 2006), subsequent charge reductions (Albonetti, 1992; Bishop and Frazier, 1984; Holmes, Daudistel, and Farrell, 1987; Shermer and Johnson, 2010), the filing of charges that trigger mandatory minimum sentences (Ulmer, Kurlychek, and Kramer, 2007), and case dismissals (Adams and Cutshall, 1987; Albonetti, 1987; Barnes and Kingsnorth, 1996; Baumer et al., 2000; Myers, 1982; Wooldredge and Thistlethwaite, 2004). However, a recent review of the empirical literature on racial and ethnic disparity in prosecution (Kutateladze, Lynn, and Liang, 2012) found that most studies were limited to the initial screening decision; only four examined more than one case processing outcome (Henning and Feder, 2005; Shermer and Johnson, 2010; Spohn and Horney, 1993; Wooldredge and Thistlethwaite, 2004) and no study investigated more than two 
decision-making points. Moreover, the evidence regarding "the effect of race and ethnicity on prosecutorial decision making is inconsistent, and it is not always blacks or Latinos and Latinas who are treated more punitively" (Kutateladze, Lynn, and Liang, 2012: 7). Some studies find evidence that race matters (Frederick and Stemen, 2012; Free Jr., 2002; Sorensen and Wallace, 1999; Ulmer, Kurlychek, and Kramer, 2007), whereas others report no direct effect of race or ethnicity in the charging process (Albonetti, 1992; Franklin, 2010; Shermer and Johnson, 2010) and a small number of studies find racial effects in charging decisions that benefit minority defendants (Holmes, Daudistel, and Farrell, 1987; Wooldredge and Thistlethwaite, 2004).

It seems likely that the inconsistency in prior findings reflects in part the fact that researchers examine different decision-making points in different jurisdictions and often focus on specific crime types. For instance, much of the prior research on prosecutorial decision making examines sexual assault, and, to a lesser extent, domestic violence cases. Because the dynamics of sexual assault and domestic violence cases are in many ways unique, it is difficult to generalize these findings to other criminal cases. This is especially true given that available evidence suggests that punitive outcomes often vary across offense types (Albonetti, 1997; Engen and Wright, 2006; Mustard, 2001; Steffensmeier, Ulmer, and Kramer, 1998; Wright and Engen, 2006). For instance, Shermer and Johnson (2010) examined charging outcomes in federal court and found that blacks and Latinos were less likely to have their initial charges reduced in weapons cases, but Latinos were more likely to have their charges reduced for drug offenses. This highlights the need to examine multiple offenses as well as the fundamental importance of investigating racial disparity for multiple case outcomes.

A largely separate literature examines racial and ethnic disparity in pretrial detention decisions (Chiricos and Bales, 1991; Demuth, 2003; Nagel, 1982; Schlesinger, 2005; Spohn, 2009; Wooldredge, 2012), which are consequential not only because they are themselves a form of punishment (Free, 2002) but also because they affect the likelihood of pleading guilty (Patterson and Lynch, 1991; Sutton, 2013), the likelihood of being convicted of a felony (Schlesinger, 2007) and the final sentences that are imposed (Schlesinger, 2007; Spohn and Holleran, 2006; Spohn, 2009; Sutton, 2013). Moreover, there is evidence that pretrial detention decisions are affected by race and ethnicity. For instance, Kutateladze, Lynn, and Liang (2012) found that four out of five 
recent studies reported racial disparity in the likelihood of detention (see also Free, 2002; Schlesinger, 2007; Sutton, 2013).

A number of scholars argue that a key limitation of extant sentencing research is its failure to consider the conditioning effects of the many consequential case processing decisions that precede the final punishment decision (Baumer, 2013; Piehl and Bushway, 2007; Ulmer, 2012). These scholars point out that focusing on a single decision-making stage (i.e., sentencing) may mask disparities originating at other discretionary points in the system. Although select work demonstrates that early charging decisions (Piehl and Bushway, 2007; Shermer and Johnson, 2010; Wright and Engen, 2006) or intermediate bail and pretrial detention decisions (Spohn, 2009; Wooldredge et al., 2011) can affect final sentencing outcomes, there are only three studies that address the issue of cumulative disparity in the prosecution and sentencing of criminal defendants (Schlesinger, 2007; Stolzenberg, D'Alessio and Eitle, 2013; Sutton, 2013). Each of these studies used different statistical techniques to analyze county-level data from the State Court Processing Statistics series and each of them reached somewhat different conclusions. One study (Schlesinger, 2007) used data on men charged with felony drug offenses to examine decisions regarding bail, pretrial detention, felony adjudication, and sentencing. The results of the analysis revealed that blacks and Latinos were treated more severely than whites at several of these decision points and, more importantly, that racial/ethnic disparities in these earlier decisions increased disparities in sentencing outcomes. In contrast, Stolzenberg and her colleagues used data on all felony defendants and a meta-analysis procedure to examine the effect of race and ethnicity on eight decision points, finding a significant overall effect for blacks but not for Hispanics (Stolzenberg, D’Alessio, and Eitle, 2013). A third approach, and one that is most similar to the approach we take, was employed by Sutton (2013), who used data on male defendants sampled in 2000 to estimate the direct and indirect effects of race and ethnicity on pretrial detention, guilty pleas, and sentence severity. Sutton (2013) found that blacks and Latinos were substantially more likely than whites to be detained prior to trial; that pretrial detention had differential effects on the likelihood of a guilty plea for whites, blacks, and Latinos; and that both pretrial detention and guilty pleas affected sentence outcomes, but the patterns of results were somewhat different for each of the three racial groups. Sutton used the results of his analysis to calculate conditional probabilities of sentence outcomes for 
defendants who were detained or released and who pled guilty or went to trial. He found that "once prior events are fully taken into account, Latinos and blacks experience about the same rather large cumulative disadvantage," but that the mechanisms that produced this cumulative disadvantage varied for defendants in the two racial groups (Sutton, 2013, p. 1217). Sutton (2013, p. 1219) concluded with a call for future research on cumulative disadvantage that "plumb[s] the murky depths of the prosecutor's office."

This study responds to Sutton's call for additional research designed to identify cumulative disadvantage in the prosecution and sentencing of criminal defendants. We build on his work by using similar analytical procedures to estimate cumulative disadvantage using a large sample of defendants charged with misdemeanors and felonies in New York City. We extend his work by incorporating charging and plea bargaining decisions made by prosecutors, examining outcomes for Asians as well as whites, blacks, and Latinos, and including proxies for social class in our models. We also investigate disparities by offense type for both misdemeanor and felony offenses. The study is guided by an integrated framework on courtroom decision making that draws upon several contemporary theoretical perspectives to develop research questions about the effects of race and ethnicity in the justice system.

\section{Theoretical Perspectives on Race, Ethnicity and Criminal Case Processing}

Numerous theoretical perspectives have been used to frame research examining the effects of race and ethnicity on criminal justice decision making, including racial threat theory (Blalock, 1967; Crawford et al., 1998), conflict theory (Chambliss and Seidman, 1971; Quinney, 1970; Turk, 1969), and uncertainty avoidance/causal attribution theory (Albonetti, 1991; Bridges and Steen, 1998). The focal concerns perspective, however, has become the primary theoretical framework guiding contemporary research in this area (Steffensmeier et al., 1998). According to the focal concerns perspective, the decisions of court actors, including prosecutors and judges, reflect their assessment of the blameworthiness or culpability of the offender, their desire to protect the community by incapacitating dangerous offenders or deterring potential offenders, and their concerns about the practical consequences, or social costs, of their decisions.

Underpinning this perspective is an understanding that case processing decisions result from a process of gathering and interpreting information about the offense, the victim (if there is a victim), and the defendant. 
Prosecutors and judges use this information to evaluate the harm done by the crime, the threat posed by the defendant, and the offender's potential for reform and rehabilitation. Their assessment of the harm done by the crime rests squarely on the seriousness and consequences of the crime. Accordingly, case processing decisions will be-at least in theory - proportionate to the harm done by the crime, which will be tied to the nature of the crime, the statutory seriousness of the offense, and, in some cases, the degree of injury to the victim.

The focal concerns perspective also suggests that criminal court actors attempt to assess defendants' blameworthiness and predict their future dangerousness. To do this, they examine the past criminal behavior of defendants, as well as their life histories and current circumstances. Defendants with long and serious criminal histories will be viewed as more culpable and blameworthy than first time defendants, and those who play primary roles will be seen as more culpable than those who are merely accomplices or who play minor roles in the offense. Social circumstances of the defendant may also matter. For instance, offenders from high crime neighborhoods may be viewed as less able to avoid the criminal influences of their surroundings.

The focal concerns perspective further proposes that charging and sentencing decisions will be affected by decision makers' concerns about the practical consequences or social costs of their decisions. They may reflect the fact that prosecutors and judges are part of a courtroom workgroup (Eisenstein and Jacob, 1977) or courthouse community (Eisenstein, Flemming, and Nardulli, 1988) with common goals and shared expectations about how cases should be handled. For example, the members of the courtroom workgroup may believe that efficiency demands a high rate of guilty pleas; consequently, plea bargaining will be encouraged and defendants who cooperate by pleading guilty will be rewarded. The members of the courthouse community may also believe that there are "normal penalties" (Sudnow, 1965) or "going rates" (Eisenstein, Flemming, and Nardulli, 1988) for particular types of crimes or particular types of offenders. Because both prosecutors and judges are concerned about maintaining relationships with other members of the courtroom workgroup and ensuring the smooth flow of cases through the system, these expectations will constrain their discretion and affect the decisions they make. Concerns about the "social costs" of punishment (e.g., the fairness of incarcerating nonviolent offenders for long periods of time or the overcrowding of jails and prisons) may also affect discretionary decisions. 
According to the focal concerns perspective, decision makers attempt to tailor outcomes to fit the facts and circumstances of each case, but in practice, they often have incomplete information about important details of the crime and the defendant. Although cases tried before a jury may provide the judge with this information, most convictions result from guilty pleas, not trials. Thus, the prosecutor and judge may know little more about the case than the facts necessary to support a guilty plea. When decision makers are faced with incomplete information and the predictions they are required to make are uncertain, defendant characteristics, such as race, gender, and social class, may be used as proxies for culpability or dangerousness. Because they do not have all the information needed to fashion sentences to fit crimes and offenders, in other words, prosecutors and judges develop "perceptual shorthands" (Hawkins, 1981) based on stereotypes and attributions that are themselves linked to defendant characteristics such as race and ethnicity. As a result, racial minorities — and particularly those who are young, male, and poor-may be treated more harshly than whites. These arguments are also consistent with broader perspectives on structural racism that suggest patterns of disadvantage evolve over time and may become institutionalized in organizational norms and decision-making routines (Bobo and Hutchings, 1996; Bobo, 1999; Myers, 1987).

Collectively, these theoretical arguments imply a consistent pattern of disadvantage for minority defendants across successive stages of criminal case processing. Importantly, though, disadvantage can occur in two interrelated ways. First, it may be "outcome-specific", meaning that racial or ethnic minorities systematically receive less favorable outcomes for certain individual case processing decisions by prosecutors and judges. For example, minority defendants may be more likely than whites to be detained prior to trial (Demuth, 2003) or to be incarcerated after conviction (Steffensmeier, Ulmer, and Kramer, 1998). However, disadvantage can also be "cumulative", in which minority defendants experience enhanced probabilities of certain combinations of less favorable case processing outcomes (DiPrete and Eirich, 2006; Hagan, 1974; Merton, 1973; Schlesinger, 2007; Spohn, 2009, Stolzenbeg, D’Alessio and Eitle, 2013; Sutton, 2013). We examine both possibilities. As such, our first hypothesis is that black and Latino defendants will be more likely than similarly-situated white defendants to experience outcome-specific disadvantages at individual stages of criminal case processing. Our second hypothesis predicts that black and Latino defendants will be more likely 
than similarly-situated white defendants to experience cumulative disadvantages across combinations of more punitive criminal case processing outcomes.

Moreover, related theoretical work suggests that negative racial stereotypes may be tied to specific offense types; stereotypical imagery is often offense-specific. In particular, black and Latino stereotypes have been problematically linked to heightened violence and perceptions of dangerousness (Kennedy, 2009; Mann et al., 2006). According to some scholars, media accounts have contributed to a persistent stereotype of a young black male as "a crack dealer...unemployed, gang affiliated, gun toting and a menace to society" (Weatherspoon, 1998: 23), whereas Latinos have been stereotyped as "foreigners, outsiders, or immigrants" who are "gang members...hot-tempered and prone to violence" (Lee, 2000: 208). The prominent role of violence in negative black and Latino imagery suggests that these stereotypes may exert greater influence in the context of violent crimes committed against persons. We therefore hypothesize that racial and ethnic disparities in prosecutorial and judicial decisions will be greater for defendants charged with person offenses, than for defendants charged with property offenses or drug offenses.

Similar theoretical arguments suggest that negative stereotypes may also be race-graded; they may attach to certain racial minority groups but not others. Although Asian-American stereotypes share a historical legacy of prejudice and negativity (Miller, 1969), contemporary imagery tied to this group has been considerably less caustic (Johnson and Betsinger, 2009). Modern social discourse increasingly identifies Asians as a "model minority" — an appellation that, although criticized (Wong et al. 1998), reflects relative social mobility, economic and educational success, and underrepresentation in serious and violent crime. Because Asian Americans are less tied to negative stereotypes in contemporary discourse they may be less likely to experience similar disadvantages as other minority groups in the justice system. We therefore expect that Asian defendants will not experience similar outcome-specific or cumulative disadvantages as black and Latino defendants.

Finally, one common criticism of research on racial disparity in punishment is that socioeconomic factors are seldom examined (Zatz, 2000). Although scholars continue to debate the 
relative importance of race and class, most acknowledge their long-standing association and the importance of attempting to disentangle their effects (Feagin, 1991; Hughes and Thomas, 1998; Wilson, 1978). Traditional conflict theories have long emphasized the importance of class-based disparities in criminal justice, arguing that the lower classes tend to be less politically and economically powerful and are therefore disproportionately targeted for enhanced punishment (Chambliss and Seidman, 1971). To the extent that socioeconomic status is associated with racial and ethnic classification, their effects will be confounded. Although, like most other studies of criminal punishment, direct measures of class status are not available in our data, we address this issue by including proxies consisting of type of attorney and neighborhood arrest location, to at least partially account for socioeconomic differences across racial and ethnic groups. More affluent defendants are more likely to be able to hire private attorneys, and stark differences exist across New York neighborhoods in socioeconomic indicators. We therefore expect that the inclusion of socioeconomic proxies will reduce the effects of race and ethnicity on outcome-specific and cumulative disadvantages in criminal case processing.

\section{The RESEARCH CONTEXT: NeW YORK COUNTY}

We test these hypotheses using unique data on racial disparity in criminal case processing in the New York County District Attorney's office (DANY). This jurisdiction is a propitious setting for a study of this type for a number of reasons. Prosecutors in Manhattan have a large and diverse criminal caseload, processing nearly 100,000 cases annually. Manhattan is also racially diverse, with large populations of whites, blacks, Latinos and Asians (U.S. Census Bureau, 2011). In addition, New York City has been the epicenter of ongoing racial justice controversies, including recent changes to the historic Rockefeller Drug Laws ${ }^{2}$ (Peters, 2009), and ongoing debates over police stop-and-frisk practices. ${ }^{3}$ Moreover, DANY has demonstrated an unusual willingness to

\footnotetext{
${ }^{2}$ The Rockefeller Drug Laws are the statutes dealing with the sale and possession of narcotics in the New York State Penal Law; they were named for then-Governor Nelson Rockefeller, who signed them in 1973. The statutes carried a minimum sentence of 15 years to life in prison, and a maximum of 25 years to life in prison for selling two ounces $(57 \mathrm{~g})$ or more of heroin, morphine, opium, cocaine, or cannabis, or possessing four ounces (113 g) or more of the same substances. In April 2009 , these statues were revised to remove the mandatory minimum sentences and to allow judges to sentence individuals convicted of drug offenses to treatment or to shorter sentences.

${ }^{3}$ In August of 2013, a federal judge ruled that the stop-and-frisk-practices of the New York Police Department violated the Fourth Amendment's protections against unreasonable search and seizure and the $14^{\text {th }}$ Amendment's provisions regarding
} 
forge a cooperative relationship with researchers to examine issues of racial justice. New York County

therefore provided a large and diverse sample of criminal cases, in a research context where emergent concerns over racial justice are paramount and where data on multiple case processing outcomes could be collected and analyzed.

\section{Criminal Case Processing in New York County}

In New York County, after defendants are arrested, police bring cases to DANY's Early Case Assessment Bureau (ECAB), where assistant district attorneys (ADAs) decide whether to accept or decline cases for prosecution. ADAs also decide what charges to bring against a defendant. Charges may increase or decrease in seriousness from arresting charges, though the former is less common. Defendants charged with felonies and misdemeanors are then brought before judges for a criminal court arraignment, which typically occurs within 24 hours of arrest (see Appendix). At arraignment, defendants are informed of pending charges, and judges decide whether to detain defendants or release them, either on bail or their own recognizance. A case in criminal court can be pled out, dismissed, or remanded for trial. Following criminal court arraignment, the offense seriousness determines subsequent case processing phases. Whereas misdemeanors are tracked to all-purpose parts of the criminal court where defendants plead and are sentenced, felonies are presented to the grand jury (unless the defendant waives this right) which either dismisses the case or indicts the defendant. Indicted cases are then forwarded to the Supreme Court, where the defendant pleads guilty and is sentenced or pleads not guilty and is scheduled for trial. Defendants can plead guilty at multiple stages of the process, and although plea offers are made by prosecutors and often include sentencing recommendations, judges must approve guilty pleas and plea offers.

\section{DATA AND METHOD}

Data for this study were collected over a 20-month period, during which researchers worked closely with DANY to identify, collect and analyze a wide range of data. ${ }^{4}$ DANY officials provided useful feedback on

equal protection under the laws. The judge ruled that the practices targeted racial minorities, stating that "the city's highest officials have turned a blind eye to the evidence that officers are conducting stops in a racially discriminatory manner (Goldstein, 2013)."

${ }^{4}$ To better understand case processing decisions and how prosecutors record relevant information, we interviewed 16 ADAs of varied levels of seniority from different trial bureaus using a semi-structured questionnaire. Information 
the office's structure and case-processing procedures; they also offered feedback on specific aspects of the research study and our interpretation of findings. Their comments informed data collection and analysis, and resulted in more nuanced and contextualized findings. They also gave us a more complete picture of the discretionary decision-making process and the range of factors that influence case-processing outcomes.

Data consist of 159,206 misdemeanors and 26,069 felonies accepted for prosecution by DANY and disposed of in 2010-2011. The misdemeanor cases include all misdemeanors, while felony cases include five commonly-occurring offense types: drug offenses, robberies, weapons offenses, burglaries and cases flagged as domestic violence. Cases were selected by "screening charge" as opposed to "arrest charge" because the latter does not represent a formal charging decision by a prosecutor; also, a "plea" or "conviction" charge was not used because many cases do not make it to these later stages.

\section{Dependent Variables}

This study examines the treatment of racial and ethnic groups across five dependent variables, beginning with the decision to file charges and ending with the decision regarding the type of sentence that is imposed. The first dependent variable is Case Acceptance, which captures the ADA's initial screening decision; it is coded 1 if the ADA files charges and 0 if the case is rejected for prosecution. The second dependent variable is Pretrial Detention, which is coded 0 for defendants who are released (on bail or on their own recognizance) and 1 for those who are detained. ${ }^{5}$ The third dependent variable is Case Dismissal, which measures whether the case is dismissed by the prosecutor or judge at any subsequent stage of criminal case processing. Dismissals may occur as the result of a motion brought by the defendant, the prosecution, or by the court's own accord. Whereas prosecutors can unilaterally dismiss charges for misdemeanors throughout the life of a case, felonies require judicial approval. Among other reasons, dismissals may result from new evidence, speedy trial problems, or adjournment in contemplation of dismissal (ACD), in which the case is adjourned for six months to a year and is dismissed contingent upon noncriminal involvement on the part of the defendant. It

generated from these interviews and discussions are not a part of research findings but they provided useful information regarding how to identify and properly code the data we received.

${ }^{5}$ Although judges make detention decisions and set bail amounts, prosecutors routinely make bail recommendations. In New York County, second-year ADAs represent the prosecutor's office at arraignment, though they often have guidance on bail requests from more experienced attorneys and requested bail amounts are generally guided by established practice. 
is coded 1 for cases that are dismissed and 0 for cases that are not (and reverse coded when examining cumulative disadvantage). The fourth dependent variable is Custodial Plea Offer, which measures whether defendants receive custodial sentence offers (i.e., an offer for a sentence to jail or prison (coded 1)) or noncustodial sentence offers (i.e., an offer that involves community service, fine, time served, or conditional discharge (coded 0)). DANY follows a so-called "best offer first" approach in which the most favorable plea offers for the defendant are given at arraignment; prosecutors can make plea offers at any point before a trial verdict, but offers become less favorable with subsequent adjournments. Plea offers for defendants with zero or one prior arrest are determined with reference to DANY's Plea Offer Guidelines, which are based on the highest pending charge and the defendant's arrest history. The guidelines do not make specific recommendations for defendants with two or more prior arrests, but they do recommend increasing sentences for defendants rearrested on the same or similar offenses. Although non-custodial offers are considered less punitive in our analysis, we recognize that there may be exceptions to this rule. For example, some defendants may view certain community punishments as less desirable than short-term incarceration (Wood and May, 2003). Receipt of a custodial plea offer does not mean that the defendant accepted the offer. All plea bargaining agreements must be approved by the judge, who is randomly assigned in most cases. Because very few felony defendants plead guilty at arraignment, which is where information on plea offers is recorded, we are only able to estimate the custodial sentence plea offer model for the misdemeanor sample. Finally, the last dependent variable is Incarceration Sentence, which captures whether a judge imposes a custodial (coded 1) or non-custodial (coded 0) sentence.

\section{Independent Variables}

The primary independent variable of interest is the race or ethnicity of the defendant, which is measured using dummy variables for white, black, Latino, Asian, and "other" defendants, with whites the omitted reference category. ${ }^{6}$ We also control for defendant's age and sex. Age is a continuous variable measured in years ${ }^{7}$ and sex is a dichotomous variable coded 1 for male defendants and 0 for female defendants.

\footnotetext{
6 The "Asian" group combines "Asian," "Chinese," and "Oriental" categories as they are reported in police reports. "Other" includes "American Indian" $(N=357)$ and those designated as "Other" in the DANY database. Defendant racial and ethnic categorization is based on arresting police officers' perception, so although it may differ from self-identification,
} 
Several additional variables are included to control for the legal characteristics of the offense. We control for the number of charges at initial screening and the number of individual criminal counts; each is measured as a continuous variable. We also include the statutory severity of the offense, which captures the seriousness of the top charge with a series of dummy variables for five felony categories (Class A to Class E felonies) and two misdemeanor categories (Class A and Class B misdemeanors). Class B misdemeanor, the least serious charge, serves as the reference category. In addition, we control for type of offense, which is measured with dummy variables for person, property and drug offenses, with "other offenses" as the reference category. ${ }^{8}$ The criminal history of the defendant is measured using two variables, one capturing whether there was a prior arrest and the other capturing whether a defendant was previously imprisoned. We include both indicators of prior record to reflect the fact that arrests are a common measure of criminal history and that prior work suggests previous incarcerations are particularly important determinants of criminal punishment (Welch, Gruhl, and Spohn, 1984). Table 1 includes descriptive summaries for both the count and dichotomous variables for prior history.

Finally, although no direct measures of social class are available in the data, two proxy variables are included that at least partially capture the socioeconomic background of defendants. The first is the type of defense counsel, which includes separate categories for private attorney (the reference group), court appointed attorney (commonly referred to as an 18(b)) attorney), and three public defender groups unique to New York City: the Legal Aid Society, the New York County Defender Services (NYCDS) and the Neighborhood Defender Service (NDS). ${ }^{9}$ The second socioeconomic proxy is the neighborhood where the arrest occurred,

it is appropriate for examining differences tied to racial perceptions of court actors. Racial classifications as recorded in arrest reports are transferred to subsequent court documents that follow the defendant through the system.

${ }^{7}$ Because some work suggests age may have curvilinear effects on incarceration (Steffensmeier et al. 1995), we also examined additional models with age and age-squared included. There was little evidence of nonlinear age effects in our data and the inclusion of the age-squared term, which although statistically significant had no effect on our estimates of racial disadvantage.

${ }^{8}$ Because the specific types of felony offenses overlapped closely with statutory severity levels (e.g. all $1^{\text {st }}$ Degree Robberies are Class A Felonies), it was not possible to include both in the model. We therefore examine statutory severity levels along with broader offense categories consisting of person, property and drug offenses.

${ }^{9}$ Court appointed panel attorneys (pursuant to Article 18(b) of the County Law) have provided legal services to indigent defendants within the Bronx and New York County Criminal courts since 1966. They are private attorneys who are compensated for representing indigent clients and they are assigned matters when a conflict prohibits institutional providers, such as The Legal Aid Society, from providing representation (see http://www.courts.state.ny.us/courts/ad1/committeesandprograms/18b/index.shtml). 
which is captured with five categories consisting of Harlem/Morningside Height, midtown to financial district West, midtown to financial district - East, and outside Manhattan, with upper west side (UWS) and upper east side (UES), the two most affluent areas in New York County, combined as the reference category. ${ }^{10}$ Although additional variables were collected and examined, such as the demographic and caseload characteristics of ADAs, missing data and limited contributions to model fit led to exclusion of these variables from final models.

\section{Analytical Approach}

To investigate racial and ethnic differences in outcome-specific and cumulative disadvantage, we estimate a series of multivariate logistic regression models. The first model includes only the racial and ethnic background of the defendant. This provides insight into baseline differences in case processing across racial and ethnic groups. The second model introduces legal control variables, which addresses concerns that racial differences may reflect differences in legal case characteristics. Finally, the third and full model incorporates all variables, including the proxies for socioeconomic characteristics — arrest neighborhood and type of defense counsel. While we consider private defense counsel as a proxy for higher socioeconomic status, alternate interpretations are possible. For example, defendants arrested for minor charges may view hiring a private attorney as an unnecessary expense, and instead rely on court-appointed counsel or a public defender.

When examining multiple discretion points, it is important to consider the possibility of selection bias caused by previous decision points. We address this issue in multiple ways. First, because pretrial detention decisions are typically made at criminal court arraignment and clearly precede other decisions (see Appendix), we include pretrial detention as a control in subsequent analyses of case dismissals, custodial plea offers and incarceration sentences. The same cannot be done for other intermediate decisions, however, because their temporal ordering is not always clear: case dismissals can happen before or after plea offers are made and we

Established in 1876, the Legal Aid Society is a private, not-for-profit legal services organization (the oldest and largest in the nation) dedicated to providing quality legal representation to low-income New Yorkers. The Society handles about 300,000 matters annually (see http://www.legal-aid.org/en/las/aboutus/ourmission.aspx).

The New York County Defender Services (NYCDS) is a not-for-profit law firm which was founded in 1997 and has since defended 1/4 of a million indigent people charged with crimes in Manhattan (see http://nycds.org/).

The Neighborhood Defender Service of Harlem (NDS) provides innovative, community-based, holistic public defense practice since 1991 to residents of upper Manhattan (see http://www.ndsny.org/index.html).

${ }^{10}$ Additional data available on defendants' home address indicated that the vast majority of the arrests were made in the neighborhoods where defendants resided. However, individual address data were missing for 50.9 percent of all cases, precluding the use of more specific geographical units in regression analyses. 
are unable to distinguish this in our data, and information on plea offers was only available for misdemeanor cases. Second, although case dismissal decisions clearly precede incarceration decisions, they cannot be included as a control in that model because all case dismissals necessarily result in no incarceration. However, we address this issue by using Heckman's correction for selection bias to account for potential bias introduced by case dismissals in our estimates for incarceration (Berk, 1983; Heckman, 1979). ${ }^{11}$

To determine whether the effects of race vary by offense type and to account for potential differences in case processing, we ran separate models for person, property, and drug offenses, each broken down by felonies versus misdemeanors. This approach also allows us to separate jail and prison sentences because misdemeanants can only receive jail sentences. Finally, to investigate cumulative racial disadvantages, we calculate predicted probabilities, separately for felonies and misdemeanors, from multivariate regression models predicting membership in different combinations of outcomes (e.g. being detained, not dismissed and incarcerated for felony offenses) (see "Cumulative Racial Disadvantage” below). Instead of focusing on individual outcomes in isolation, this approach allows us to compare the relative probabilities of different racial and ethnic groups experiencing compound disadvantages that are associated with multiple negative case processing outcomes.

As discussed in additional detail below, the first dependent variable, Case Acceptance, lacked sufficient variation — the vast majority of cases were initially accepted for prosecution—so separate regression analyses are not reported for that outcome. We do report descriptive statistics for this initial outcome, though, because the high case acceptance rate is itself an important finding and because it helps provide context for subsequent results, such as the relatively high rate of subsequent cases dismissals (see Discussion). As noted above, the analyses of Plea Offers were necessarily limited to misdemeanor cases because plea bargains for felony cases were seldom made at arraignment and were therefore not reliably recorded in the data. Final sentencing outcomes in felony cases may therefore reflect important elements of prosecutorial plea bargaining discretion as

\footnotetext{
${ }^{11}$ Specifically, the heckprobit command in STATA was used to specify a probit model with sample selection based on case dismissals using maximum likelihood estimation. Estimates from this model, therefore, represent the effects of race and ethnicity on incarceration after accounting for selection effects associated with case dismissals. For consistency, probit coefficients were converted to logits and are reported in odds ratios for interpretation. In line with prior work (Bushway, Johnson, and Slocum, 2007), we examined these models to ensure that they did not exceed established thresholds for problematic levels of collinearity (Condition Number $=22.19$ ).
} 
well as judicial sentencing discretion. All other analyses report the full results for all cases for each outcome of interest.

\section{RESULTS}

\section{DESCRIPTIVE ANALYSIS}

Table 1 reports descriptive statistics for the dependent and independent variables for each of the racial and ethnic groups included in the analysis. New York County is somewhat unique in that almost all of the cases brought by the police to DANY's Early Case Assessment Bureau (ECAB) for screening are accepted for prosecution; overall, 96 percent of all misdemeanor and felony cases resulted in prosecution. This was strikingly consistent across race and ethnicity, with only nominal differences existing among groups. Office policy at DANY was clearly to accept the vast majority of cases at initial screening, which we consider in greater detail in the discussion section of the paper.

Approximately one-quarter of defendants received pretrial detention, with some notable racial differences emerging. Only 7 percent of Asian defendants were detained, compared to 32 percent of black defendants. Whites and Latinos fell in between, with detention rates of 17 percent and 24 percent, respectively. Subsequent case dismissals occurred in 22 percent of cases. Less pronounced racial differences characterized this outcome and the differences that did emerge reflected somewhat harsher treatment of whites. The dismissal rate was 20 percent for white defendants, compared to 21 percent for blacks, 25 percent for Latinos, and 23 percent for Asians. There were, on the other hand, striking racial differences in the likelihood that defendants charged with a misdemeanor would receive a custodial plea offer. One-third of all defendants received plea offers for custodial sentences, but the rates ranged from 8 percent for Asian defendants to 22 percent for white defendants, 32 percent for Latino defendants, and 46 percent for black defendants. Similar differences emerged for the incarceration rate, which was 27 percent overall but was 9 percent for Asians, 21 percent for whites, 25 percent for Latinos, and 32 percent for blacks.

\section{[INSERT TABLE 1 ABOUT HERE]}

Table 1 also reveals that the average age of defendants in the sample was 34 years old, and more than 80 percent of defendants were male. Defendant age and sex were fairly consistent across racial groups, though 
Latino defendants were slightly younger (32 years) and a smaller percentage of Asian defendants were male (66 percent). On average, defendants were charged with 1.77 charges and 1.9 counts, with relatively small differences across racial and ethnic groups. The majority of all defendants, 68 percent, were charged with Class A Misdemeanors. Although a relatively small proportion of the total sample was charged with serious felonies, black and Latino defendants tended to be overrepresented and Asian defendants tended to be underrepresented in these categories. Asian defendants also were notably underrepresented in drug offenses and overrepresented in property crimes compared to other racial/ethnic groups. Although not shown in Table 1, among defendants with non-drug felony charges, whites were more likely to have burglary charges, blacks and Latinos were more likely to have robbery charges, and Asians were more likely to be involved in domestic violence. For the misdemeanor cases, marijuana offenses were most common for white and Latino defendants, whereas theftrelated offenses were most common for black and especially Asian defendants.

Some of the most pronounced racial differences emerged for prior record. On average, defendants had 3.5 prior arrests and 12 percent had previously served time in prison. ${ }^{12}$ The number of prior arrests averaged 5.05 for black defendants and 2.52 for Latino defendants, compared to 1.90 for white defendants and .85 for Asian defendants. Only 1 percent of Asians and 4 percent of whites had previously been in prison; by contrast, the rates were 9 percent for Latinos and 18 percent for blacks. In terms of defense counsel, most defendants, regardless of race, were represented by legal aid attorneys, but white and Asian defendants were substantially more likely than black and Latino defendants to have private attorneys. White and especially Asian defendants were most likely to be arrested in Midtown West, whereas black and Latino defendants were arrested most often in Harlem.

\section{OUTCOME-SPECIFIC RACIAL DisAdVANTAge}

Although the differences in case outcomes documented in Table 1 suggest that Latinos and, especially, blacks are treated more harshly than whites and Asians in terms of pretrial detention, plea bargaining, and sentence type, these disparities may reflect the fact that there are race-based differences in legally relevant

\footnotetext{
${ }^{12}$ Prior arrest may not always serve as a measure of threat or dangerousness given that (a) not all prior arrests are the same (e.g., prior marijuana arrest versus robbery arrest), (b) some suspects may be innocent, and (c) there may be racial disparities in police arrest practices. Unfortunately, no data were available on the offense types for prior arrests so we are unable to capture these subtleties in our analysis.
} 
indicators of crime seriousness and criminal history and in our proxies for socioeconomic status. To test for this, we estimate a series of multivariate models for each of our dependent variables (except case acceptance) to examine outcome-specific disadvantages. As noted above, Model 1 includes only race and ethnicity, Model 2 introduces legal controls and Model 3 adds the proxy measures of socioeconomic status. Table 2 reports the results of these analyses, beginning with pretrial detention and ending with the final sentencing decision. ${ }^{13}$

As shown in the first column of Table 2, there is strong evidence that blacks and, to a lesser extent, Latinos were significantly more likely than whites to be detained at arraignment. The inclusion of legal controls in Model 2 reduced but did not eliminate these differences. Controlling for defense counsel and arrest neighborhood in Model 3 further reduced the magnitude of the racial differences but they remained statistically significant. The inclusion of each set of additional controls significantly improved model fit, and the final estimates indicate that compared to whites, the odds of detention were 47.8 percent greater for blacks and 14.4 percent higher for Latinos. Among all racial groups, Asians were clearly the least likely to be detained after arraignment. In addition, defendants faced greater odds of pretrial detention if they were older, male, had more charges at screening, had more serious criminal histories, and were represented by any one of the four institutional providers rather than private counsel. The data also showed marked differences in detention status between defendants charged with felonies and misdemeanors. Overall, 56.2 percent of felony defendants were detained compared to just 17 percent of those charged with misdemeanors. For felonies, 61.3 percent of blacks, 55.6 percent of Latinos, 43.2 percent of whites and 27.5 percent of Asians were detained; for misdemeanors, the detention rates were 22.5 percent for blacks, 15.3 percent for Latinos, 10.3 percent for whites and 3.3 percent for Asians. Not surprisingly, defendants with more serious charges were more likely to be detained at arraignment.

\section{[INSERT TABLE 2 ABOUT HERE]}

A contrary pattern of findings emerged for racial differences in case dismissals. Somewhat surprisingly, white defendants were the least likely to have their cases dismissed, and black and Latino defendants were the most likely. This somewhat counterintuitive finding highlights the importance of examining racial disparity for multiple case processing decisions. Inclusion of legal controls in Model 2 increased the effect for black and

\footnotetext{
${ }^{13}$ In the interest of space, only the odds ratios are reported in the table, though full results including the unstandardized coefficients and standard errors are available in the on-line appendix.
} 
Latino defendants, whereas the addition of socioeconomic proxies in Model 3 decreased them slightly, with the final estimates indicating that the odds of case dismissal were 34.6 percent greater for blacks, 34.5 percent greater for Latinos, and 8.4 percent greater for Asian defendants compared to similarly-situated white defendants. Notably, pretrial detention exerted a strong effect on the probability of case dismissal, with detained suspects about one-third as likely to have their cases dismissed as defendants who were released at arraignment. The general pattern of results also suggested that defendants arrested in less-affluent areas were less likely to have their cases dismissed. The exception was for Harlem, where defendants had slightly greater odds of case dismissal. The likelihood of case dismissal was also higher for defendants who were facing less serious charges, had fewer charges at screening, and were represented by appointed counsel. ${ }^{14}$ Somewhat surprisingly, prior record increased the odds of dismissal. As discussed below, the predicted estimates for case dismissal change somewhat when assessing this outcome separately by offense category, suggesting that the pattern for case dismissal varies by both offense type and severity.

Given that plea bargaining rarely occurs for felonies at criminal court arraignment (which is when this information is recorded), we focus the analysis of plea offers on misdemeanor cases. Of the 98,557 misdemeanor defendants whose cases advanced to this stage, 36.1 percent received custodial sentence plea offers and 63.9 percent received offers for non-incarcerative alternatives. ${ }^{15}$ Overall, black and Latino defendants were far more likely than white defendants to receive custodial sentence plea offers. Even after controlling for legally-relevant factors in Model 2, the odds of receiving a custodial plea offer were 69.8 percent greater for blacks and 21.2 percent greater for Latinos compared to white defendants. Inclusion of socioeconomic measures in Model 3 had little effect on these estimates. In contrast, Asian defendants were only about onethird as likely as similarly-situated white defendants to receive custodial sentence offers in misdemeanor offenses. The analyses also suggest that the probability of receiving a custodial sentence offer was greater for

\footnotetext{
${ }^{14}$ Supplemental analyses were also conducted on the subsample of cases for which information was available for ADA characteristics $(N=88,476)$. These results suggest cases were slightly less likely to be dismissed when ADAs had fewer open cases (odds ratio $=0.997, \mathrm{p}<.001)$ and were female (odds ratio $=0.893, \mathrm{p}<.001)$, Latino $($ odds ratio $=0.806, \mathrm{p}<$ .001 ) or Asian (odds ratio $=0.891, \mathrm{p}<.001$ ) rather than white. Cases were slightly more likely to be dismissed when ADAs were black (odds ratio $=1.078, \mathrm{p}<.001$ ). Overall, though, the effects of ADA characteristics were substantively small and because they were only available for about half of all cases, they are not included in the final models reported. ${ }^{15}$ Among non-custodial plea offers, 22.2 percent involved community service, 13.5 percent a fine, 11.1 percent time served, 1.7 percent a Treatment Readiness Program, and 15.5 percent involved undisclosed “other” offers.
} 
defendants who were male, older, and detained prior to trial. Those who had a more serious misdemeanor charge, were charged with person offenses, had more charges and more counts, and were represented by any type of counsel other than a private defense attorney also had greater odds of receiving a custodial plea. Also, consistent with DANY's plea guidelines, misdemeanor defendants with more prior arrests (as well as those who had previously served time in prison) were substantially more likely to receive plea offers involving incarceration.

Turning to the results of our analysis of the type of sentence imposed, Table 2 reveals that black and Latino defendants were more likely than white defendants to receive incarceration sentences (Model 1). ${ }^{16}$ This is not surprising given that the vast majority of convictions result from guilty pleas, and plea offers in misdemeanor cases were more likely to involve custodial offers for these defendants. ${ }^{17}$ The magnitudes of the racial differences were substantially mitigated when legally-relevant controls were introduced in Model 2, and they were further reduced when proxies for socioeconomic status were included in Model 3, but they remained statistically significant for black defendants. ${ }^{18}$ Overall, the odds of receiving a custodial punishment were 30.0 percent greater for blacks when compared to similarly-situated white defendants. Asian defendants were substantially less likely to be incarcerated compared to other racial groups. In line with previous research, incarceration was also more likely in cases involving the most serious offenses and the most experienced repeat offenders (Spohn, 2006; Zatz, 2000). Also consistent with prior work, pretrial detention was positively associated with incarceration, which again highlights the importance of examining successive stages of criminal

\footnotetext{
${ }^{16}$ In the interest of space, jail and prison sentences were combined for these analyses. However, we include offense seriousness variables that distinguish between misdemeanor and felony cases to account for differences in types of confinement, and subsequent models were also estimated that were disaggregated by felonies (involving prison sentences of one year or more) and misdemeanors (less than one year in jail). Some important variations emerged in these analyses which are reported in Table 3.

${ }^{17}$ To investigate the relationship between plea offers and final sentences, supplemental analyses were run including custodial plea as an additional predictor of incarceration sentences in Model 3. Because information on plea offers was only available for misdemeanor cases, though, this analysis has to be restricted to the subsample of misdemeanor cases. As one might expect, the plea offer variable had a very strong effect on the final sentencing decision, with a custodial plea increasing the odds of incarceration by a factor of 17.5. The effects for black and Latino defendants were reduced to nonsignificance in this model, though Asian defendants continued to be less likely to be incarcerated than white defendants. This analysis provides some evidence that racial disparities in sentencing are tied to the plea bargaining process, though future research is needed to examine this relationship in felony cases as well.

${ }^{18}$ Note that prior to correcting for sampling bias caused by the elimination of dismissed cases at the sentencing stage (see Analytical Approach), differences between white and Latino defendants were larger and statistically significant $(\mathrm{OR}=$ $1.156, p<0.5$ prior to performing the Heckman procedure). For black defendants, the procedure did not result in a noticeable difference.
} 
case processing (Spohn, 2009). Older, male defendants and defendants with more charges were also more likely to receive incarceration, as were defendants represented by any of the four institutional providers rather than a private attorney, and defendants arrested in less affluent neighborhoods.

We hypothesized that black and Latino defendants, but not Asian defendants, would be treated more harshly than white defendants. The results of our multivariate analyses of post-charging decisions provide somewhat mixed support for these hypotheses. Consistent with our expectations, black and to a lesser degree Latino defendants were treated more harshly than white defendants in terms of pretrial detention, custodial sentence plea offers and likelihood of incarceration. However, contrary to expectations, blacks and Latinos had greater odds of case dismissal than did whites. We also found, as predicted, that Asians received the least punitive outcomes for all four dependent variables. The next set of analyses further examines differences in racial and ethnic disadvantage by offense type.

\section{OUTCOME-SPECIFIC RACIAL DiSADVANTAGE BY OFFENSE TYPE}

Given that prior research suggests racial disparity may vary by type of offense (Albonetti, 1997; Mustard, 2001; Steffensmeier et al., 1998), the regression analyses were disaggregated by person, property and drug offenses, and examined separately for felonies and misdemeanors. ${ }^{19}$ This provides a more nuanced examination of custodial plea offers in misdemeanor cases. It also allows for the separation of incarceration sentences into jail (i.e. misdemeanors) and prison (i.e. felony) sentences (Holleran and Spohn, 2004; Wang and Mears, 2010; Wang et al., 2013). All variables in Table 2 were included in these models, but in the interest of space, only the odds ratios for race and ethnicity are reported in Table 3 and discussed.

Although the general pattern of racial disparities was relatively consistent across offense types, the magnitude of racial differences varied in interesting ways. Across offense types black and Latino defendants were more likely than white defendants to be detained, to receive custodial sentence plea offers and to be incarcerated, but they were also more likely to benefit from cases dismissals. The findings for Asian defendants were less consistent but in general suggested they were less likely to be detained, to receive custodial sentence offers, and to be incarcerated relative to white defendants.

\footnotetext{
${ }^{19}$ Person offenses - New York Penal Law $\$ 120.00-135.75$; property offenses - $\$ 140.00-165.74$; and drug offenses $\$ 220.00-221.55$. All other offenses were grouped as the "other" category.
} 


\section{[INSERT TABLE 3 ABOUT HERE]}

For person offenses, racial disparities were greater for misdemeanors than felonies across nearly all discretion points. Compared to whites, blacks were more than twice as likely to be detained, nearly three times as likely to receive a custodial plea offer, and nearly twice as likely to be sentenced to jail for misdemeanor person offenses. This is consistent with some work that suggests less serious offenses involve greater discretion which may be associated with larger racial disparities (Spohn and Cederbloom, 1991). Moreover, racial differences in case dismissals for person offenses were notably driven by misdemeanor cases. No significant differences emerged in case dismissals for violent felony crimes. Latino disadvantage for person offenses was less pronounced than black disadvantage. Latinos were more likely than whites to be detained for both felony and misdemeanor violent offenses, but differences for custodial pleas and incarceration were not statistically significant.

For property offenses, similar patterns emerged, although generally less pronounced. Again, black defendants were more likely to be detained and incarcerated for both misdemeanor and felony property offenses, but they were also more likely to have their cases dismissed. Similar results again emerged for Latinos though they were not significantly more likely to be sentenced to jail for misdemeanor property offenses. Both blacks and Latinos were significantly more likely to receive custodial pleas in misdemeanor property cases, though these effects were noticeably less pronounced than for person offenses.

A similar pattern of findings emerged for drug offenses, but fewer of the racial and ethnic contrasts were statistically significant. Black defendants were more likely to be detained and incarcerated for felony drug offenses whereas Latinos were more likely to be incarcerated but not detained prior to trial. No racial differences emerged in pretrial detention for misdemeanor drug offenses, but very large differences emerged for custodial pleas in drug cases. Although both black and Latinos were more likely to have their cases dismissed in misdemeanor drug offenses, blacks were more than three times as likely to receive custodial plea offers and Latinos were more than twice as likely. Overall, the largest racial disadvantages occurred for black defendants charged with person and drug misdemeanors, where they were substantially more likely than comparable white defendants to be detained, offered custodial pleas and sentenced to jail. 
The pattern for Asian defendants was completely different. They tended to be treated more favorably than comparable white defendants across individual outcomes of interest. The only exceptions to this were for the incarceration decision in felony person offenses, where the odds for Asian defendants being sentenced to imprisonment were 93.3 percent greater than white defendants and for misdemeanor property offenses where they were slightly less likely than whites to have their cases dismissed. Otherwise they received relative leniency across pretrial detention, dismissals, custodial sentence plea offers and sentences imposed. Asian defendants received particular advantages for pretrial detention, custodial plea offers, and incarceration sentences in misdemeanor property offenses, the majority of which were related to larceny (19 percent) and theft (40 percent). Overall, there appears to be clear evidence that Asian defendants do not experience comparable disadvantages as blacks and Latinos, or even whites.

\section{Cumulative RaCial Disadvantage}

In order to provide some additional insight into the cumulative disadvantages that can occur across multiple stages of prosecution and sentencing, Table 4 reports predicted probabilities for different combinations of outcomes for each racial and ethnic group. ${ }^{20}$ These predicted probabilities were calculated separately for felony and misdemeanor cases from multivariate regression models predicting membership in different combinations of outcomes (e.g. being detained, not dismissed and incarcerated for felony offenses). ${ }^{21}$

Combinations that involve multiple disadvantages across individual outcomes are considered more punitive, so defendants who are both detained and imprisoned are considered to be more disadvantaged than defendants who are only detained or only imprisoned. Results from this analysis of cumulative disadvantage are reported in Table 4.

For felony offenses, the most disadvantaged combination of outcomes involved pretrial detention, case retention (non-dismissal) and incarceration (see A in Table 4). The likelihood of this combination was greatest, for black defendants (33 percent) followed by Latinos (30 percent). Controlling for all other predictors in the

\footnotetext{
${ }^{20}$ Predicted probabilities were calculated using the margins command in STATA12 with other variables held constant at their means.

${ }^{21}$ All combinations are reported for felony offenses. For misdemeanors, only the most commonly-occurring groupings are reported because several combinations were extremely unlikely for all groups (e.g. predicted probabilities were one percent or smaller for cases involving pretrial detention, no dismissal, custodial plea and no jail sentence). Results for the full range of all possible misdemeanor combinations are available from the authors by request.
} 
model, the predicted probability of the most cumulative disadvantages was 5 percent greater for blacks and about 2 percent greater for Latinos, compared to whites. Asians were clearly the least likely group to experience the most severe cumulative disadvantages (15 percent). In fact, they were 13 percent less likely than white defendants to receive this combination. Although these differences in probabilities may appear to be relatively small on the surface, they can result in substantial aggregate differences in punishment among racial and ethnic groups. For example, applying these predicted probabilities to our data suggests that 361 additional black felony defendants received the most severe combination of outcomes than would have been expected if they had been white. $^{22}$

Other notable differences emerge from the predicted probabilities for felony offenses in Table 4 . White and Asian defendants are both more likely than black and Latino defendants to receive non-incarceration sentences in combination with pretrial detention and non-dismissals. Whites and Asians are also more likely than blacks and Latinos to experience no incarceration in combination with pretrial release (no detention) and non-dismissals (see D). In fact, this is the most likely combination of outcomes for Asian felony defendants, who are 10 percent more likely than black defendants to receive this combination. Finally, Asian defendants are also the group most likely to be released and to have their cases dismissed (see F), whereas blacks and Latinos are the most likely groups to be detained prior to trial and having their cases dismissed (see E). Although the latter finding suggests blacks and Latinos benefit from high dismissal rates, it also raises important questions about the use of pretrial detention in cases that are ultimately dropped. Overall, the general pattern of findings suggests that Asian defendants tend to receive the least disadvantaged and black and Latinos often received the most disadvantaged combination of outcomes.

\section{[INSERT TABLE 4 ABOUT HERE]}

For misdemeanor offenses, the combination of outcomes that was by far the most common was no detention, no dismissal, no custodial plea and no incarceration (see J). This relatively lenient constellation of

\footnotetext{
${ }^{22}$ To get a measure of how many more black felony defendants experienced this outcome than would have been expected if they were white, we took the number of black felony defendants $(N=7,226)$ times the probability of the most punitive combination of outcomes (.33) and subtracted the predicted number of the most punitive combination based on white defendants, but again using the number of black felony defendants for the calculation $\left(7,226^{*} .28\right)$, so as not to reflect the fact that there are more black than white defendants in the sample.
} 
outcomes was most common for Asian defendants (60 percent) followed by white defendants (56 percent), with Latino defendants (52 percent) and black defendants (49 percent) the least likely to be punished in this way. Asian defendants were again the most likely group to experience the least severe punishment combination involving no detainment, no custodial plea offer and a case dismissal (see K). As with felony cases, black misdemeanants were the group most likely to receive the most disadvantaged combination of outcomes (being detained, not dismissed, receiving a custodial plea offer and being jailed; see G), though these punitive combinations were relatively rare and racial differences were relatively small for the most severe outcomes. Examining the overall pattern of findings for cumulative disadvantage in misdemeanor offenses suggests that Asians are least likely whereas blacks are most likely to receive the most disadvantaged combinations.

\section{DISCUSSION}

The current study investigated racial and ethnic disparity across multiple prosecutorial and judicial decisions using data on all misdemeanors and a selection of felonies disposed of by the New York County DA's Office (DANY) in 2010-2011. It was guided by five theoretically-grounded predictions regarding the punitive treatment of racial and ethnic minority groups. Our first hypothesis was that black and Latino defendants would be significantly disadvantaged across multiple prosecution and sentencing outcomes. Conditional support was found for this expectation. Because nearly all cases were accepted for initial prosecution in New York County, we were unable to model this outcome. The high case acceptance rate may reflect several factors. There may be informal case filtering processes that precede initial case acceptance that are not captured in our data, or the rate may reflect DANY's intentional efforts to maintain a positive relationship with the New York Police Department by initially prosecuting the majority of arrests. Some prior work also suggests that different courthouse cultures develop their own unique case processing norms over time (Eisenstein and Jacob, 1977), so DANY's high acceptance rate may simply reflect the cultural norms of this jurisdiction. This explanation seems to be consistent with DANY's use of multiple post-case-screening stages as a downstream mechanism for filtering out non-meritorious cases (see Appendix) — whereas DANY had very high initial acceptance rates, it also experienced relatively high case dismissal rates. 
Of the remaining discretionary points in the system, strong evidence emerged for racial and ethnic disparity in pretrial detention, plea offers, and the use of incarceration. Black and Latino defendants were significantly disadvantaged for each of these outcomes. Unexpectedly, though, they had higher odds than white defendants of case dismissal. This finding, which is consistent with some prior research (Petersilia, 1983), raises the question of whether higher dismissal rates for defendants of color should be viewed as an indicator of leniency, or simply as a mechanism for declining cases which would have been rejected at initial screening had that process been more thorough. One possibility is that police are more willing to arrest blacks and Latinos even when there is insufficient evidence to support prosecution. This is consistent with the fact that defendants with more serious prior records also had higher likelihoods of case dismissal, which may reflect the fact that law enforcement officials view some defendants as "the usual suspects" and, as a result, are willing to arrest in cases with marginal evidence for prosecution. An alternative or complementary explanation is that cases involving black and Latino defendants had higher dismissal rates because victims or witnesses in these cases were less likely to appear for pretrial proceedings; the fact that cases processed in Harlem had higher dismissal rates than those processed in more affluent areas of the city adds some credence to this possibility. Given that we do not have data on why cases were dismissed (although prosecutors we spoke with mentioned lack of evidence and speedy trial constraints), these explanations are highly speculative. There clearly is a need for additional research designed to identify the reasons that cases are dismissed and to determine if these reasons vary by the defendant's race and ethnicity as well as prior criminal history.

The fact that blacks and Latinos were treated more severely for some but not all outcomes highlights the importance of examining multiple discretionary points in the justice system. If we had examined only case dismissals, as some prior work has done (Albonetti, 1987; Barnes and Kingsnorth, 1996; Spohn, 2001), we would have mistakenly concluded that blacks and Latinos were treated more leniently than whites, even though they received more severe outcomes at all other stages of the system. The importance of examining multiple outcomes is further supported by our finding that pretrial detention had a strong and statistically significant effect on the likelihood of a custodial plea offer and on the likelihood of incarceration. Our results suggest that 
race and ethnicity have direct positive effects on pretrial detention, custodial sentence plea offers and sentence type as well as indirect effects on custodial plea offers and sentence type through pretrial detention.

In line with our second hypothesis, we also found some evidence for cumulative disadvantages that characterized certain constellations of punitive decision-making outcomes. In particular, black defendants, and to a lesser extent Latino defendants, were more likely to receive the most disadvantaged combinations for felony crimes; they were both more likely than similar white defendants to be detained, not dismissed and subsequently incarcerated. Similar findings characterized misdemeanor crimes, where blacks, and to a lesser extent Latinos, were underrepresented in the relatively lenient modal combinatory category which consisted of no detainment, no dismissal, no custodial plea and no incarceration. Even when dismissals are considered, blacks and Latinos remain underrepresented in the least severe punishment combinations for misdemeanor crimes.

Although research on cumulative disadvantages in the justice system remains in its infancy, the current findings are largely consistent with recent work on the topic (Sutton, 2013; Stolzenberg et al. 2013). Like Sutton (2013), we find that certain combinations of discretionary court decisions can accumulate to produce racial disparity in punishment. An essential direction for future work in this area will be the development of more sophisticated statistical models, such as decision-tree models, that are specifically designed to account for the multiple and interrelated stages of criminal cases processing. Ultimately, these types of approaches to cumulative disadvantage may be combined with other recent advances in statistical modeling of case processing outcomes, such as the use of propensity score matching, hierarchical modeling approaches and path analysis (Brennan, 2006; Johnson, 2006; Kurlychek and Johnson, 2010). The current findings suggest that racial disadvantages can vary across decision-making points in the justice system, that they are likely to have both direct and indirect effects, and that overall black and Latino defendants tend to experience more severe cumulative outcomes.

Our third hypothesis was that black and Latino disadvantage would be especially pronounced for violent crimes, where racial stereotypes are likely to be most salient. This prediction also received qualified support. The racial differences in the likelihood of pretrial detention, custodial plea offer, and incarceration were particularly pronounced for misdemeanor person offenses, especially in comparison with property crimes. We 
also found some evidence of greater disparities for drug offenses in both felony and misdemeanor offenses. For felony drug crimes, black defendants faced particularly high odds of being detained and, for misdemeanor drug crimes, both blacks and Latinos had especially high odds of receiving custodial sentence plea offers. This is not surprising, given that racial stereotypes sometimes include negative imagery that also ties blacks and Latinos to the illegal drug trade (Weatherspoon, 1998).

Our fourth hypothesis was that, because Asian-American defendants have not been systematically tied to negative stereotypes in the ways that black and Latino defendants have been, they would not be subject to the same types of disadvantage as blacks and Latinos. Strong support was found for this prediction. In fact, Asian defendants overall tended to receive the most favorable outcomes. Compared to whites, Asians were substantially less likely to be detained, to receive a custodial sentence plea offer, and to be incarcerated. Asians also had higher odds of case dismissal than whites, though the difference was much smaller than for blacks and Latinos. Case processing outcomes were particularly favorable for Asians charged with misdemeanor property offenses, where they were especially unlikely to be held in pretrial detention, to receive custodial sentence plea offers, or to be incarcerated. These findings are consistent with theoretical notions about racial typing in assessments of offense gravity. Hawkins (1987), for instance, suggests that a member of a given racial group will receive the harshest punishment for committing those crimes perceived to be racially inappropriate. To the extent that property crimes are stereotyped to be most appropriate for Asian defendants, then, this may contribute to the particularly lenient case outcomes for Asian defendants in these cases. More work is needed on court actor perceptions of racially-appropriate offense typing to substantiate this possibility.

Our final hypothesis was that racial and ethnic disparities would be reduced by the inclusion of proxies for socioeconomic status. Although no direct measures of social class were available, we argue that both the type of attorney and the neighborhood of arrest are likely to indirectly capture differences in defendant socioeconomic status. Poorer defendants are unlikely to be able to afford private attorneys and stark socioeconomic differences characterize different geographical areas of Manhattan. Inclusion of the neighborhood variable may also help account for other influences, such as the arresting behavior of police or community-level differences in informal social capital. Consistent with expectations, racial and ethnic effects 
were reduced when these additional predictors were included in the model; however, controlling for these factors did not "explain away" the racial and ethnic disparities found for each case outcome. The current findings therefore offer some tentative support for the expectation that racial differences in case processing might be partially tied to socioeconomic differences; however, as we discuss below, improved measures are needed to fully explore this relationship.

Overall, our findings offer some qualified support for our theoretical predictions. For all of the outcomes examined except case dismissal, we found harsher treatment for black and Latinos defendants. We also found some evidence of cumulative racial disadvantage in combinations of more severe sets of discretionary outcomes. These findings are consistent with theoretical expectations rooted in attribution and focal concerns perspectives that suggest when court actors are faced with organizational uncertainty they may draw upon racial stereotypes to assess individual culpability and community protection concerns (Albonetti, 1991; Steffensmeier et al. 1998). In the face of incomplete information, race may serve as a key decisionmaking proxy for offender dangerousness, threat and culpability. Such findings are also consistent with an emerging corpus of work on implicit racial bias in the justice system (Levinson and Smith, 2012). This research suggests that court actors, despite their egalitarian ideals, are often influenced by the automatic and subconscious classification of information in racially-coded ways that can systematically disadvantage racial minority defendants. Some recent work finds evidence of implicit race bias in judges (Rachlinski, et al. 2009) though comparable work on prosecutors has yet to be conducted. Uniting the social psychological insights from implicit bias theory with contemporary perspectives on the focal concerns of courtroom decision making offers a promising future direction for theoretical advancement in our understanding of race and punishment.

Along with race and ethnicity, several other predictors also explained our case processing outcomes. Consistent with the theoretical expectations of the focal concerns perspective, legal indicators of increased culpability and dangerousness were strongly associated with punishment severity. In particular, defendants with more serious criminal histories, charged with more serious offenses, and facing more charges received more severe outcomes. Offenders who were older and male also received harsher punishments. These results suggest that prosecutors and judges use both legally relevant indicators of defendants' current and past criminality along 
with other defendant characteristics to determine their dangerousness, threat, blame, and potential for reform. As they attempt to utilize the limited and incomplete information available to them, prosecutors and judges may also draw upon stereotypes tied to offender characteristics to assess relative culpability and community threat. Although our findings are consistent with these theoretical arguments, like most prior research on unwarranted disparity, we lack direct measures of these focal concerns at sentencing. Improved tests of these theoretical arguments will therefore need to begin to incorporate more proximate and detailed measures of offender culpability, danger, risk and other relevant considerations at sentencing. Such endeavors will likely require mixed methods and creative analytical approaches in future work.

\section{CONCLUSION}

As Albonetti (1990: 315) and others have recognized, "Research on the criminalization process has indicated an interdependence across decisions. ... Decision making at one stage of court processing affects subsequent decisions, either limiting choices of action and/or creating an operational context within which punitive sanctions are imposed." Criminal punishment involves a dynamic process of decision making. As criminal suspects are processed through the justice system, a number of different case processing decisions are made that individually or cumulatively determine the fate of individual defendants. The vast majority of empirical research remains limited to only a snapshot of this more dynamic punishment process, and very little research examines early case processing decisions controlled by prosecutors or their subsequent effects on downstream punishments.

The current study contributed to existing research on race and punishment in a number of important ways. It collected and analyzed unique data from a large urban jurisdiction, included a broad sample of misdemeanor and felony cases and a diverse group of racial and ethnic defendants, and examined multiple case processing outcomes from initial case acceptance through final sentencing. Prior work on racial disparity has been dominated by single-stage studies primarily examining the final sentence for felony offenders, and focusing almost exclusively on black and white, or more recently black, white and Latino comparisons (Baumer, 2013). Only a handful of prior studies have investigated cumulative disadvantages in criminal case processing (Schlesinger, 2007; Stolzenberg, D'Alessio and Eitle, 2013; Sutton, 2013). Our research represents an effort to 
contribute to and advance that work. We include seldom-investigated prosecutorial outcomes such as custodial sentence plea offers. We also examine misdemeanor offenses, which a number of scholars have suggested might be particularly prone to racial and ethnic bias given the discretion inherent in decision making in these cases (Brennan, 2006; Spohn and Cederblom, 1991). Our study also includes a relatively large sample of Asian defendants, broadening the scope of empirical inquiry and providing for interesting contrasts in the findings of different racial minority groups, and it examines how racial disparity estimates vary by offense type and how they are affected by the inclusion of proxies for socioeconomic status.

Perhaps most importantly, this research was closely informed by the cooperative partnership forged with the district attorneys' office where the study was conducted. At each stage of the research process, from initial data collection through final analysis, invaluable practitioner feedback was provided from a variety of sources, including office executives, line prosecutors, and analysts, regarding the many unique nuances of case processing in the jurisdiction. This cooperative model yielded a rich trove of knowledge about the office structure, case-processing details, data strengths and limitations, and the context of the findings.

Despite its significant contributions, though, this research also has some important limitations. Examining them provides useful insight for improving future research on racial disparity in criminal case processing. Data for this study came from the district attorney office's case-management system. Although it included a broad host of relevant variables, it was not built for research purposes, and therefore it lacked some important information. Unfortunately, one important weakness of the current study is that no reliable measures of the strength of the evidence in the case were available. Usable indicators of evidentiary strength are notoriously difficult to capture and are seldom available in case management data (Shermer and Johnson, 2009). A clear priority of future research on case processing outcomes, then, is to collect improved measures of quality of arrest and strength of evidence to examine how these might affect racial and ethnic disparity across stages of the justice system. It seems unlikely, though, that quality of evidence could explain the racial differences we observe. Evidentiary strength should be most important for early outcomes like case acceptance or dismissals, and we find the least evidence of disparity at these stages. For other outcomes, like pretrial detention and incarceration, racial differences are pronounced and unlikely to be attributable to evidentiary concerns. 
Furthermore, because DANY does not systematically capture victim information, we were not able to examine offender-victim dyads for violent offenses. Some research suggests that the race of victim can affect racial disparity in punishment (Paternoster et al., 2003), so future research on criminal case processing in person offenses should strive to collect additional information on victim characteristics. We include rough proxies for socioeconomic conditions, but future work is needed that incorporates improved measures of defendant class status. This study suggests that the ability to hire a private attorney minimizes one's chance of pretrial detention and custodial sentence outcomes. It is also likely that other indicators of class status are important, such as educational attainment, employment status, or yearly income. Family factors and community ties might also matter, particularly for certain decision-making stages, such as pretrial detention and release, that are explicitly tied to these considerations. As such, collection of additional information on defendant socioeconomic and social status should be a priority in future research on racial disparity in case processing.

An advantage of this study over others is its inclusion of Asian defendants. Our findings suggest that there are important racial differences in case processing that extend beyond white, black and Latino categories. Nonetheless, we were unable to differentiate among defendants using more refined categories of racial and ethnic identity. For example, important differences may exist within these broad racial and ethnic categories in terms of skin tone, language skills, country of origin, citizenship, or other elements of racial and ethnic identity. These types of refinements hold the potential to make important contributions in future work of unwarranted disparity in the justice system. Also, while examining multiple decision points was a clear strength of the study, individual decision points require further exploration. For example, the data did not permit disaggregation of case dismissal findings by case processing phases and criminal justice actors (e.g., what proportion of dismissals was made by prosecutors independently, by prosecutors with judicial approval, by judges or the grand jury). Data constraints on defendants' probation status also limited our ability to examine the relationship between technical violations and case non-dismissals. Future studies should look beyond the dichotomous operationalization of dismissals and explore more developed measures of this vital discretion point.

Furthermore, although this study examines several important intermediate case processing decisions, it does not capture the initial behavior of law enforcement agents, who have substantial discretion in deciding 
which defendants to arrest (Black and Reiss, 1970). A substantial body of work has developed that documents racial influences in policing (e.g. Smith, Visher, and Davidson, 1984; Stewart et al. 2009; Warren et al. 2006), and recently New York City has become an epicenter of the ongoing debate over race and police discretion, ${ }^{23}$ so this is clearly an important direction for future work to pursue. Similarly, we are unable to investigate the postsentencing decisions of correctional officers, who also exercise important discretion over certain outcomes such as parole revocations (Lin, 2010). Police behavior can have important influences on prosecutorial decisionmaking, and pronounced punishments can be altered by back-end sentencing adjustments so future work needs to begin to expand the ken of discretionary outcomes that may affect racial disparity in criminal case processing outcomes.

Although the findings of this study should have broad appeal—DANY is nationally recognized and influential prosecutors' office so its decisions are likely to affect practices in other district attorney's offices-it is also important to note that New York County is in many ways unique, which may limit the generalizability of our results. We study a large, urban, racially and ethnically diverse county so our findings need to be replicated in other jurisdictions that are smaller and more racially and ethnically homogenous. It is our hope that future studies will apply the conceptual and analytical approach developed here to additional outcomes in multiple and diverse jurisdictions. Traditionally, research on the justice system has been divided into studies of policing, courts, or corrections, but it may be time to begin examining the broader nexus among different domains of the system - for the pursuit of racial justice ultimately will require thoughtful examination of the many diverse and interrelated discretionary components of the entirety of the formal criminal punishment process.

${ }^{23}$ In 2009, the Rockefeller Drug Laws were amended due to what some argued was their disproportionately punitive effect on communities of color, and in November 2013, Bill de Blasio won New York City's mayoral election promising to end discriminatory stop-and-frisk policing practices toward young black and Latino men. 


\section{REFERENCES}

Adams, Kenneth and Charles R. Cutshall. 1987. Refusing to prosecute minor offenses: The relative influence of legal and extralegal factors. Justice Quarterly 4 (4): 595-609.

Albonetti, Celesta A. 1992. Charge reduction: An analysis of prosecutorial Discretion in Burglary and Robbery Cases. Journal of Quantitative Criminology 8 (3): 317-333.

Albonetti, Celesta A. 1991. An integration of theories to explain judicial discretion. Social Problems. 38: 247266.

Albonetti, Celesta A. 1987. Prosecutorial discretion: the effects of uncertainty. Law and Society Review: 291313.

Albonetti, Celesta A. 1990. Race and the probability of pleading guilty. Journal of Quantitative Criminology 6 (3): 315-334.

Albonetti, Celesta A. 1997. Sentencing under the federal sentencing guidelines: Effects of defendant characteristics, guilty pleas, and departures on sentence outcomes for drug offenses, 1991-1992. Law and Society Review: 789-822.

Barnes, Carole Wolff and Rodney Kingsnorth. 1996. Race, drug, and criminal sentencing: Hidden effects of the criminal law. Journal of Criminal Justice 24 (1): 39-55.

Baumer, Eric P. 2013. Reassessing and redirecting research on race and sentencing. Justice Quarterly 30 (2): 231-261.

Baumer, Eric P., Steven F. Messner, and Richard B. Felson. 2000. The role of victim characteristics in the disposition of murder cases. Justice Quarterly 17 (2): 281-307.

Beichner, Dawn and Cassia Spohn. 2005. Prosecutorial charging decisions in sexual assault cases: Examining the impact of a specialized prosecution unit. Criminal Justice Policy Review 16 (4): 461-498.

Bishop, Donna M. and Charles E. Frazier. 1984. The effects of gender on charge reduction. The Sociological Quarterly 25 (3): 385-396.

Blalock, Hubert M. 1967. Toward a Theory of Minority-Group Relations. n.p.: Wiley. Book Review Digest Retrospective: 1903-1982 (H.W. Wilson), EBSCOhost (accessed August 21, 2013).

Blumstein, Alfred, Jacqueline Cohen, Susan E. Martin, and Michael H. Tonry. 1983. Research on Sentencing: The Search for Reform, Volume I. Washington, DC: National Academy Press.

Bobo, Lawrence D. 1999. Prejudice as group position: Microfoundations of a sociological approach to racism and race relations. Journal of Social Issues 55 (3): 445-472.

Bobo, Lawrence and Vincent L. Hutchings. 1996. Perceptions of racial group competition: Extending blumer's theory of group position to a multiracial social context. American Sociological Review: 951-972.

Brennan, Pauline K. 2006. Sentencing female misdemeanants: An examination of the direct and indirect effects of race/ethnicity. Justice Quarterly 23(1):60-95. 
Bridges, George S. and Sara Steen. 1998. Racial disparities in official assessments of juvenile offenders: Attributional stereotypes as mediating mechanisms. American Sociological Review 63 (4): 554-570.

Bushway, Shawn D., Brian D. Johnson, and Lee Ann Slocum. 2007. Is the magic still there? The use of the Heckman two-step correction for selection bias in Criminology. Journal of Quantitative Criminology 23:151-178

Carson, E. Ann and William J. Sabol. 2012. Prisoners in 2011. Washington, DC: Bureau of Justice Statistics.

Chambliss, William J. and Robert B. Seidman. 1971. Law, Order, and Power. Reading, MA: Addison-Wesley.

Chiricos, Theodore G. and William D. Bales. 1991. Unemployment and punishment: An empirical assessment. Criminology 29 (4): 701-724.

Crawford, Charles, Ted Chiricos, and Gary Kleck. 1998. Race, racial threat, and sentencing of habitual offenders. Criminology 36: 481-512.

Demuth, Stephen. 2003. Racial and ethnic differences in pretrial release decisions and outcomes: A comparison of Hispanic, black, and white felony arrestees. Criminology 41: 873-908.

DiPrete, Thomas A. and Gregory M. Eirich. 2006. Cumulative advantage as a mechanism for inequality: A review of theoretical and empirical developments. Annual Review of Sociology 32: 271-297.

Eisenstein, James, Roy B. Flemming, and Peter F. Nardulli. 1988. The Contours of Justice: Communities and Their Courts. Boston, MA: Little, Brown and Co.

Eisenstein, James and Herbert Jacob. 1977. Felony Justice: An Organizational Analysis of Felony Courts. Boston, MA: Little, Brown.

Engen, Rodney L. and Ronald F. Wright. 2006. The effects of depth and distance in a criminal code on charging, sentencing, and prosecutor power. North Carolina Law Review 84 (6): 1935-1982.

Feagin, Joe R. 1991. The continuing significance of race: Antiblack discrimination in public places. American Sociological Review 56: 101-116.

Federal Bureau of Investigation. 2011. Crime in the United States 2011: Uniform Crime Reports. Washington, DC: United States Government Printing.

Forst, Brian. 2002. "Prosecution." In Crime: Public Policies for Crime Control, edited by James Q. Wilson and Joan Petersilia. 2nd ed., 509-536. Oakland, CA: ICS Press.

Franklin, Travis W. 2010. The intersection of defendants' race, gender, and age in prosecutorial decision making. Journal of Criminal Justice 38: 185-192.

Frazier, Patricia A. and Beth Haney. 1996. Sexual assault cases in the legal system: Police, prosecutor, and victim perspectives. Law and Human Behavior 20 (6): 607-628.

Frederick, Bruce and Don Stemen. 2012. Anatomy of Discretion: An Analysis of Prosecutorial Decision Making-Summary Report. New York, NY: Vera Institute of Justice. 
Free Jr., Marvin D. 2002. Race and presentencing decisions in the United States: A summary and critique of the research. Criminal Justice Review 27 (2): 203-232.

Goldstein, Joseph. 2013. Judge rejects New York’s stop-and-frisk policy. New York Times. August 12.

Hagan, John. 1974. Parameters of criminal prosecution: an application of path analysis to a problem of criminal justice. The Journal of Criminal Law and Criminology 65 (4): 536-544.

Hagan, John, Carla Shedd, and Monique R. Payne. 2005. Race, ethnicity, and youth perceptions of criminal injustice. American Sociological Review 70 (3): 381-407.

Hagan, John and Celesta Albonetti. 1982. Race, class, and the perception of criminal injustice in America. American Journal of Sociology 88 (2): 329-355.

Hawkins, Darnell F. 1987. Beyond anomalies: Rethinking the conflict perspective on race and criminal punishment. Social Forces 65 (3): 719-745.

Hawkins, Darnell F. 1981. Causal attribution and punishment for crime. Deviant Behavior 2 (3): 207-230.

Heckman, James J. 1979. Sample selection bias as a specification error. Econometrica 47: 153-161.

Henning, Kris and Lynette Feder. 2005. Criminal prosecution of domestic violence offenses an investigation of factors predictive of court outcomes. Criminal Justice and Behavior 32 (6): 612-642.

Holmes, Malcolm D., Howard C. Daudistel, and Ronald A. Farrell. 1987. Determinants of charge reductions and final dispositions in cases of burglary and robbery. Journal of Research in Crime and Delinquency 24 (3): 233-254.

Hughes, Michael and Melvin E. Thomas. 1998. The continuing significance of race revisited: a study of race, class, and quality of life in America, 1972 to 1996. American Sociological Review: 785-795.

Johnson, Brian D. 2003. Racial and ethnic disparities in sentencing departures across modes of conviction. Criminology 41: 449.

Johnson, Brian D. and Sara Betsinger. 2009. Punishing the "model minority": Asian-American criminal sentencing outcomes in Federal District Courts. Criminology 47 (4): 1045-1090.

Johnson, Brian D. 2006. The Multilevel Context of Criminal Sentencing: Integrating Judge and County Level Influences. Criminology 44(2): 259-298.

Kennedy, Joseph E. 2009. The Jena Six, mass incarceration, and the remoralization of civil rights. Harvard Civil Rights-Civil Liberties Law Review 44: 477-509.

Kramer, John and Darrell Steffensmeier. 1993. Race and imprisonment decisions. The Sociological Quarterly 34 (2): 357-376.

Kurlychek, Megan and Brian D. Johnson. 2010. Juvenility and punishment: Sentencing juveniles in adult criminal court. Criminology 48(3): 725-758. 
Kutateladze, B., V. Lynn, and E. Liang. 2012. Do Race and Ethnicity Matter in Prosecution? New York, NY: Vera Institute of Justice.

LaFree, Gary. 1998. Losing Legitimacy: Street Crime and the Decline of Social Institutions in America. Boulder, CO: Westview Press, Inc.

LaFree, GD. 1980. Effect of sexual stratification by race on official reactions to rape. American Sociological Review 45 (5): 842-854.

Lee, Jennifer. 2000. The salience of race in everyday life black customers' shopping experiences in black and white neighborhoods. Work and Occupations 27 (3): 353-376.

Levinson, Justin D. and Robert J. Smith. 2012. Implicit Racial Bias Across the Law. Cambridge, UK: Cambridge University Press.

Lin, Jeffrey. 2010. Parole revocation in the era of mass incarceration. Sociology Compass 4 (12): 999-1010.

Merton, Robert K. 1973. “The Matthew Effect in Science.” Pp. 439-459 in The Sociology of Science: Theoretical and Empirical Investigations, edited by N.W. Storer. Chicago: University of Chicago Press.

Miller, Stuart Creighton. 1969. Unwelcome Immigrant: American Image of the Chinese, 1785-1882. California: University of California Press.

Mitchell, Ojmarrh. 2005. A meta-analysis of race and sentencing research: Explaining the inconsistencies. Journal of Quantitative Criminology 21 (4): 439-466.

Mustard, David B. 2001. Racial, ethnic, and gender disparities in sentencing: Evidence from the US Federal Courts. Journal of Law and Economics 44 (1): 285-314.

Myers, Martha A. 1982. Common law in action: The prosecution of felonies and misdemeanors. Sociological Inquiry 52 (1): 1-15.

Myers, Martha A. 1987. Economic inequality and discrimination in sentencing. Social Forces 65 (3): 746-766.

Nagel, Ilene H. 1982. Legal/extra-legal controversy: Judicial decisions in pretrial release. Law and Society Review.17: 481-515.

Paternoster, Raymond, Robert Brame, Sarah Bacon, Andrew Ditchfield, Karen Beckman, and Nadine Frederique. 2003. "An Empirical Analysis of Maryland's Death Sentencing System with Respect to the Influence of Race and Legal Jurisdiction." Department of Criminology, University of Maryland, College Park, MD. Unpublished Manuscript.

Patterson, E. Britt and Micheal Lynch. 1991. "Bias in Formalized Bail Procedures." In Race and Criminal Justice," edited by E. Britt Patterson and Michael Lynch, 36-53. New York, NY: Harrow and Heston.

Peters, Jeremy W. 2009. Albany Reaches Deal to Repeal '70s Drug Laws. New York Times. March 25.

Petersilia, Joan. 1983. Racial Disparities in the Criminal Justice System. Santa Monica, CA: Rand Corporation. 
Peterson, Ruth D. and John Hagan. 1984. Changing conceptions of race: Towards an account of anomalous findings of sentencing research. American Sociological Review: 56-70.

Piehl, Anne Morrison and Shawn D. Bushway. 2007. Measuring and explaining charge bargaining. Journal of Quantitative Criminology 23 (2): 105-125.

Quinney, Richard. 1970. The Social Reality of Crime. New Brunswick, NJ: Transaction Publishers.

Schlesinger, Traci. 2005. Racial and ethnic disparity in pretrial criminal processing. Justice Quarterly 22 (2): 170-192.

Shermer, Lauren O'Neill and Brian D. Johnson. 2010. Criminal prosecutions: Examining prosecutorial discretion and charge reductions in U.S. Federal District Courts. Justice Quarterly 27 (3): 394-430.

Smith, Doug, Christy Visher and Laura A. Davidson. 1984. "Equity and discretionary justice: the influence of race on police arrest decisions." Journal of Criminal Law \& Criminology. 75(1): 234-249.

Sorensen, Jon and Donald H. Wallace. 1999. Prosecutorial discretion in seeking death: An analysis of racial disparity in the pretrial stages of case processing in a midwestern county. Justice Quarterly 16 (3): 559-578.

Spears, Jeffrey W. and Cassia C. Spohn. 1997. The effect of evidence factors and victim characteristics on prosecutors' charging decisions in sexual assault cases. Justice Quarterly 14 (3): 501-524.

Spohn, Cassia. 2009. How do Judges Decide?: The Search for Fairness and Justice in Punishment Thousand Oaks, CA: SAGE Publications Inc.

Spohn, Cassia. 2000. Thirty years of sentencing reform: The quest for a racially neutral sentencing process. Criminal Justice 3: 427-501.

Spohn, Cassia. 2011. Unwarranted disparity in the wake of the Booker/Fanfan decision. Criminology and Public Policy 10 (4): 1119-1127.

Spohn, Cassia, Dawn Beichner, and Erika Davis-Frenzel. 2001. Prosecutorial justifications for sexual assault case rejection: Guarding the "gateway to justice." Social Problems 48 (2): 206-235.

Spohn, Cassia and Jerry Cederblom. 1991. Race and disparities in sentencing: A test of the liberation hypothesis. Justice Quarterly 8(3): 305-327.

Spohn, Cassia, John Gruhl, and Susan Welch. 1981. The effect of race on sentencing: A re-examination of an unsettled question. Law and Society Review 16: 71-88.

Spohn, Cassia and David Holleran. 2006. The imprisonment penalty paid by young, unemployed black and Hispanic male offenders. Criminology 38 (1): 281-306.

Spohn, Cassia. 2001. Prosecuting sexual assault: A comparison of charging decisions in sexual assault cases involving strangers, acquaintances, and intimate partners. Justice Quarterly 18 (3): 651-688.

Spohn, Cassia and Julie Homey. 1993. Rape law reform and the effect of victim characteristics on case processing. Journal of Quantitative Criminology 9 (4): 383-409. 
Steen, Sara, Rodney L. Engen, and Randy R. Gainey. 2005. Images of danger and culpability: Racial stereotyping, case processing, and criminal sentencing. Criminology 43 (2): 435-468.

Steffensmeier, Darrell, Jeffery Ulmer, and John Kramer. 1998. The interaction of race, gender, and age in criminal sentencing: the punishment cost of being young, black, and male. Criminology 36 (4): 763-798.

Stewart, Eric., Eric P. Baumer, Rod K. Brunson, and Ronald L. Simsons. 2009. Neighborhood racial context and discrimination. Criminology 47(3): 847-87.

Sudnow, David. 1965. Normal crimes: Sociological features of the penal code in a public defender office. Social Problems 12 (3): 255-276.

Turk, Austin T. 1969. Criminality and Legal Order. Chicago, IL: Rand McNally.

Tyler, Tom R. 2007. "Racial Profiling, Attributions of Motive, and the Acceptance of Social Authority." In Social Consciousness and Legal Decision Making: Psychological Perspective, edited by Richard L. Wiener, Brian H. Bornstein, Robert Schopp and Steven L. Willborn, 61-74. New York, NY: Springer Science, Business Media.

U.S. Census Bureau. 2011. State and County Quick Facts 2011.Retrieved August 20, 2013, from the United States Census Bureau website: http://quickfacts.census.gov/qfd/states/00000.html.

Ulmer, Jeffery T. and Brian Johnson. 2004. Sentencing in context: A multilevel analysis. Criminology 42 (1): 137-178.

Ulmer, Jeffery T., Megan C. Kurlychek, and John H. Kramer. 2007. Prosecutorial discretion and the imposition of mandatory minimum sentences. Journal of Research in Crime and Delinquency 44 (4): 427-458.

Ulmer, Jeffery T. 2012. Recent developments and new directions in sentencing research. Justice Quarterly 29 (1): $1-40$.

Wang, Xia and Daniel P. Mears. 2010. A multilevel test of minority threat effects on sentencing. Journal of Quantitative Criminology 26 (2): 191-215.

Wang, Xia, Daniel P. Mears, Cassia Spohn, and Lisa Dario. 2013. Assessing the differential effects of race and ethnicity on sentence outcomes under different sentencing systems." Crime \& Delinquency, 59(1): 87-114.

Warren, Patricia, Donald Tomaskovic-Devey, William Smith, Matthew Zingraff, and Marcinda Mason. 2006. Drivine while black: Bias processes and racial disparity in police stops. Criminology 44(3): 709-738.

Weatherspoon, Floyd D. 1998. African-American Males and the Law: Cases and Materials. Lanham, MD: University Press of America.

Welch, Susan, John Gruhl, and Cassia Spohn. 1984. Dismissal, conviction, and incarceration of Hispanic defendants: a comparison with Anglos and blacks. Social Science Quarterly 65 (2): 257-264.

Wilson, William J. 1978. The Declining Significance of Race: Blacks and Changing American Institutions. University of Chicago Press. 
Wong, Paul, Chienping Faith Lai, Richard Nagasawa, and Tieming Lin. 1998. Asian Americans as a model minority: self-perceptions and perceptions by other racial groups. Sociological Perspectives 41: 95-118.

Wooldredge, John, Timothy Griffin, Amy Thistlethwaite, and Fritz Rauschenberg. 2011. Victim-based effects on racially disparate sentencing in Ohio. Journal of Empirical Legal Studies 8 (1): 85-117.

Wooldredge, John and Amy Thistlethwaite. 2004. Bilevel disparities in court dispositions for intimate assault. Criminology 42 (2): 417-456.

Wooldredge, John. 2012. Distinguishing race effects on pre-trial release and sentencing decisions. Justice Quarterly 29 (1): 41-75.

Wright, Ronald and Rodney Engen. 2006. The effects of depth and distance in a criminal code on charging, sentencing, and prosecutor power. North Carolina Law Review 84 (6).

Zatz, Marjorie S. 2000. The convergence of race, ethnicity, gender, and class on court decisionmaking: looking toward the 21st Century. Criminal Justice 3: 503-552.

Zatz, Marjorie S. 1984. Race, ethnicity, and determinate sentencing. Criminology 22 (2): 147-171. 
Table 1. Descriptive Statistics for Dependent and Independent Variables by Race and Ethnicity

\begin{tabular}{|c|c|c|c|c|c|}
\hline & All Cases & White & Black & Latino & Asian \\
\hline & Mean (SD) & \multicolumn{4}{|c|}{ Mean (SD) } \\
\hline \multicolumn{6}{|l|}{ Dependent Variables } \\
\hline Case acceptance & $.96(0.21)$ & $.96(0.20)$ & $.96(0.21)$ & $.95(0.21)$ & $.97(0.17)$ \\
\hline Pretrial detention & $.26(0.44)$ & $.17(0.37)$ & $.32(0.47)$ & $.24(0.43)$ & $.07(0.25)$ \\
\hline Case dismissal & $.22(0.42)$ & $.20(0.40)$ & $.21(0.41)$ & $.25(0.43)$ & $.23(0.42)$ \\
\hline Custodial plea offer & $.33(0.47)$ & $.22(0.42)$ & $.46(0.50)$ & $.32(0.46)$ & $.08(0.26)$ \\
\hline Incarceration sentence & $.27(0.45)$ & $.21(0.41)$ & $.32(0.46)$ & $.25(0.43)$ & $.09(0.28)$ \\
\hline \multicolumn{6}{|l|}{ Independent Variables } \\
\hline \multicolumn{6}{|l|}{ Defendant Characteristics } \\
\hline Age & $33.81(12.65)$ & $34.87(12.64)$ & $34.86(13.00)$ & $31.67(11.95)$ & $35.85(12.10)$ \\
\hline Male & $.83(0.37)$ & $.82(0.39)$ & $.83(0.37)$ & $.86(0.35)$ & $.66(0.47)$ \\
\hline \multicolumn{6}{|l|}{ Charging Characteristics } \\
\hline Number of charges & $1.77(0.84)$ & $1.79(0.84)$ & $1.77(0.84)$ & $1.77(0.85)$ & $1.63(0.77)$ \\
\hline Number of counts & $1.90(2.24)$ & $1.94(2.23)$ & $1.90(1.82)$ & $1.89(2.37)$ & $1.81(2.58)$ \\
\hline \multicolumn{6}{|l|}{ Statutory Severity } \\
\hline Class A felony & $.002(0.05)$ & $.001(0.04)$ & $.002(0.04)$ & $.004(0.07)$ & $.001(0.03)$ \\
\hline Class B felony & $.03(0.17)$ & $.01(0.12)$ & $.03(0.18)$ & $.04(0.18)$ & $.01(0.08)$ \\
\hline Class C felony & $.02(0.14)$ & $.01(0.11)$ & $.03(0.16)$ & $.02(0.15)$ & $.01(0.11)$ \\
\hline Class D felony & $.05(0.23)$ & $.05(0.22)$ & $.06(0.24)$ & $.06(0.23)$ & $.04(0.19)$ \\
\hline Class E felony & $.03(0.16)$ & $.03(0.17)$ & $.03(0.17)$ & $.03(0.16)$ & $.03(0.17)$ \\
\hline Class A misdemeanor & $.68(0.47)$ & $.72(0.45)$ & $.72(0.45)$ & $.70(0.46)$ & $.83(0.38)$ \\
\hline Class B misdemeanor & $.14(0.34)$ & $.17(0.37)$ & $.13(0.34)$ & $.16(0.37)$ & $.08(0.27)$ \\
\hline \multicolumn{6}{|l|}{ Offense Type } \\
\hline Person & $.08(0.26)$ & $.08(0.26)$ & $.07(0.25)$ & $.08(0.28)$ & $.07(0.26)$ \\
\hline Property & $.34(0.47)$ & $.33(0.47)$ & $.35(0.48)$ & $.31(0.46)$ & $.44(0.50)$ \\
\hline Drug & $.21(0.40)$ & $.20(0.40)$ & $.21(0.40)$ & $.23(0.42)$ & $.06(0.24)$ \\
\hline \multicolumn{6}{|l|}{ Prior Record } \\
\hline Prior arrests (count) & $3.53(8.53)$ & $1.90(6.42)$ & $5.05(10.64)$ & $2.52(5.73)$ & $.85(3.46)$ \\
\hline Prior prison sentences (count) & $.12(0.46)$ & $.04(0.29)$ & $.18(0.55)$ & $.09(0.40)$ & $.01(0.14)$ \\
\hline At least one prior arrest & $.47(0.50)$ & $.26(0.44)$ & $.58(0.49)$ & $.46(0.50)$ & $.20(0.40)$ \\
\hline At least one prior prison sent & $.09(0.28)$ & $.03(0.17)$ & $.12(0.33)$ & $.07(0.25)$ & $.01(0.08)$ \\
\hline \multicolumn{6}{|l|}{ Defense Counsel } \\
\hline Legal Aid & $.71(0.45)$ & $.68(0.47)$ & $.72(0.45)$ & $.71(0.45)$ & $.70(0.46)$ \\
\hline $18(b)^{\mathrm{a}}$ & $.08(0.27)$ & $.07(0.25)$ & $.09(0.28)$ & $.09(0.28)$ & $.08(0.27)$ \\
\hline NYCDS & $.13(0.33)$ & $.09(0.29)$ & $.14(0.34)$ & $.13(0.34)$ & $.08(0.28)$ \\
\hline NDS & $.03(0.17)$ & $.01(0.09)$ & $.03(0.18)$ & $.03(0.18)$ & $.01(0.08)$ \\
\hline Private counsel & $.05(0.22)$ & $.15(0.36)$ & $.02(0.14)$ & $.04(0.20)$ & $.13(0.33)$ \\
\hline \multicolumn{6}{|l|}{ Arrest Neighborhood } \\
\hline Upper West/East Side & $.11(0.31)$ & $.10(0.30)$ & $.10(0.31)$ & $.13(0.34)$ & $.04(0.21)$ \\
\hline Harlem & $.38(0.49)$ & $.13(0.34)$ & $.44(0.50)$ & $.45(0.50)$ & $.08(0.27)$ \\
\hline MTDT -West & $.42(0.49)$ & $.59(0.49)$ & $.39(0.49)$ & $.34(0.47)$ & $.76(0.42)$ \\
\hline MTDT -East & $.06(0.23)$ & $.12(0.32)$ & $.04(0.19)$ & $.05(0.23)$ & $.08(0.27)$ \\
\hline Outside Manhattan & $.03(0.17)$ & $.06(0.23)$ & $.02(0.15)$ & $.03(0.16)$ & $.04(0.19)$ \\
\hline$N$ & 195,098 & 28,190 & 90,365 & 65,494 & 8,535 \\
\hline
\end{tabular}

NOTE: Descriptive statistics for the "Other Race" category are not shown but are available from the authors by request.

ABBREVIATIONS: $\mathrm{SD}=$ Standard Deviation; MTDT $=$ midtown to downtown; NYCDS = the New York County Defender Services; NDS = the

Neighborhood Defender Service.

${ }^{a}$ Court appointed panel attorneys (pursuant to Article 18(b) of the County Law). 
Table 2: Odds Ratios Predicting Pretrial Detention, Dismissal, Custodial Pleas, and Incarceration

\begin{tabular}{|c|c|c|c|c|c|c|c|c|c|c|c|c|}
\hline \multirow[b]{2}{*}{ Variables } & \multicolumn{3}{|c|}{ Pretrial Detention } & \multicolumn{3}{|c|}{ Dismissal } & \multicolumn{3}{|c|}{ Custodial Plea Offer } & \multicolumn{3}{|c|}{ Incarceration Sentence } \\
\hline & Model 1 & Model 2 & Model 3 & Model 1 & Model 2 & Model 3 & Model 1 & Model 2 & Model 3 & Model 1 & Model 2 & Model 3 \\
\hline Black & $2.396^{*}$ & $1.551^{*}$ & $1.478 *$ & 1.137 & $1.458^{*}$ & $1.346^{*}$ & $3.041^{*}$ & $1.698^{*}$ & $1.666^{*}$ & $1.794 *$ & $1.277^{*}$ & $1.300^{*}$ \\
\hline Latino & $1.615^{*}$ & $1.163^{*}$ & $1.144^{*}$ & $1.395^{*}$ & $1.496^{*}$ & $1.345^{*}$ & $1.614 *$ & $1.212 *$ & $1.212 *$ & $1.524 *$ & 1.006 & 1.028 \\
\hline Asian & $0.342^{*}$ & $0.453^{*}$ & $0.411^{*}$ & $1.162^{*}$ & 1.030 & $1.084 *$ & $0.288^{*}$ & $0.354 *$ & $0.330 *$ & $0.731 *$ & $0.504 *$ & $0.490^{*}$ \\
\hline Other & 0.825 & 0.787 & 0.842 & $1.522 *$ & $1.463^{*}$ & $1.276^{*}$ & 0.955 & 0.912 & 0.919 & 1.230 & 0.895 & 0.877 \\
\hline Age & & $1.015^{*}$ & $1.018^{*}$ & & 1.002 & 0.998 & & $1.030 *$ & $1.030 *$ & & $1.020^{*}$ & $1.021^{*}$ \\
\hline Male & & $1.995^{*}$ & $2.018^{*}$ & & 1.014 & 0.992 & & $1.473 *$ & $1.427 *$ & & $1.512^{*}$ & $1.508^{*}$ \\
\hline Detained & & - & - & & $0.344 *$ & $0.331^{*}$ & & $1.112^{*}$ & $1.105^{*}$ & & $1.053^{*}$ & $1.043^{*}$ \\
\hline A misdemeanor & & $2.253^{*}$ & $2.171^{*}$ & & $1.193^{*}$ & $1.226^{*}$ & & $1.988 *$ & $1.966^{*}$ & & $2.530^{*}$ & $2.515^{*}$ \\
\hline E felony & & $10.27 *$ & $10.44 *$ & & $1.465^{*}$ & $1.653^{*}$ & & - & - & & $9.389^{*}$ & $9.283^{*}$ \\
\hline D felony & & $10.08^{*}$ & $10.19^{*}$ & & $1.420^{*}$ & $1.570^{*}$ & & - & - & & $9.366^{*}$ & $9.102^{*}$ \\
\hline C felony & & $21.59^{*}$ & $22.80^{*}$ & & $2.181^{*}$ & $2.332 *$ & & - & - & & $16.644^{*}$ & $16.966^{*}$ \\
\hline B felony & & $21.29^{*}$ & $21.28^{*}$ & & $1.474^{*}$ & $1.507^{*}$ & & - & - & & $14.380^{*}$ & $14.230 *$ \\
\hline A felony & & $118.3^{*}$ & $165.4^{*}$ & & $1.096^{*}$ & $1.206^{*}$ & & - & - & & $42.083^{*}$ & $41.961 *$ \\
\hline Person crime & & $2.000^{*}$ & $2.000^{*}$ & & $3.407^{*}$ & $3.400 *$ & & $5.661 *$ & $5.473^{*}$ & & $1.369^{*}$ & $1.411^{*}$ \\
\hline Property crime & & $1.859^{*}$ & $1.824 *$ & & 1.069 & 1.097 & & $2.807 *$ & $2.743 *$ & & $1.487^{*}$ & $1.447 *$ \\
\hline Drug crime & & $1.978^{*}$ & $2.053^{*}$ & & 1.010 & 0.918 & & $3.837^{*}$ & $3.864 *$ & & $1.783^{*}$ & $1.829 *$ \\
\hline Charges & & $1.274^{*}$ & $1.290^{*}$ & & $0.866^{*}$ & $0.851^{*}$ & & 1.097 & 1.109 & & $1.431^{*}$ & $1.439^{*}$ \\
\hline
\end{tabular}




\section{Pretrial Detention}

Dismissal

Custodial Plea Offer

Incarceration Sentence

\begin{tabular}{|c|c|c|c|c|c|c|c|c|c|c|c|c|}
\hline \multirow{2}{*}{ Variables } & \multirow[b]{2}{*}{ Model 1} & \multirow{2}{*}{\multicolumn{2}{|c|}{ Model 2 Model 3}} & & & \\
\hline & & & & Model 1 & Model 2 & Model 3 & Model 1 & Model 2 & Model 3 & Model 1 & Model 2 & Model 3 \\
\hline Counts & & 1.015 & $1.015^{*}$ & & 1.000 & 1.003 & & $1.097 *$ & $1.089 *$ & & $1.277 *$ & $1.006 *$ \\
\hline Prior arrest & & $3.875^{*}$ & $3.815^{*}$ & & $1.290 *$ & $1.354 *$ & & $5.723 *$ & $5.769 *$ & & $1.006 *$ & $4.072 *$ \\
\hline Prior prison & & $3.637 *$ & $3.505^{*}$ & & $1.033^{*}$ & $1.077 *$ & & $4.461 *$ & $4.460 *$ & & $0.504 *$ & $2.786^{*}$ \\
\hline Legal aid & & & $2.408 *$ & & & $0.823^{*}$ & & & $2.042 *$ & & & $1.265^{*}$ \\
\hline $18(b)^{a}$ & & & $3.110 *$ & & & $1.292 *$ & & & $3.325^{*}$ & & & $1.554^{*}$ \\
\hline NYCDS & & & $2.866^{*}$ & & & $0.821 *$ & & & $2.938^{*}$ & & & $1.525^{*}$ \\
\hline NDS & & & $2.118 *$ & & & 1.136 & & & $1.551 *$ & & & $1.134 *$ \\
\hline Harlem & & & $0.916^{*}$ & & & $1.088 *$ & & & 0.996 & & & 1.001 \\
\hline MTDT -West & & & $1.102 *$ & & & $0.787^{*}$ & & & $1.189 *$ & & & $1.181 *$ \\
\hline MTDT -East & & & $1.100 *$ & & & $0.877 *$ & & & 1.028 & & & $1.103 *$ \\
\hline Outside NYC & & & $1.066^{*}$ & & & $0.776^{*}$ & & & $1.101 *$ & & & $1.316^{*}$ \\
\hline Constant & $0.202 *$ & $0.004 *$ & $0.002 *$ & $0.272 *$ & $0.488 *$ & $0.498 *$ & $0.286^{*}$ & $0.019 *$ & $0.002 *$ & $0.459 *$ & $0.004 *$ & $0.003 *$ \\
\hline Pseudo $R^{2}$ & .026 & .279 & .292 & .002 & .272 & .266 & .046 & .262 & .303 & .016 & .189 & .190 \\
\hline$-2 L L$ & 121,566 & 89,827 & 82,675 & 205,417 & 134,389 & 124,555 & 121,902 & 92,865 & 86,156 & 328,096 & 303,640 & 280,338 \\
\hline$N^{\mathrm{b}}$ & 108,450 & 108,280 & 100,510 & 184,305 & 176,108 & 164,748 & 97,472 & 95,113 & 93,588 & 136,607 & 136,604 & 128,909 \\
\hline
\end{tabular}

ABBREVIATIONS: MTDT = midtown to downtown; NYCDS = the New York County Defender Services; NDS = the Neighborhood Defender Service.

${ }^{a}$ Court appointed panel attorneys (pursuant to Article 18(b) of the County Law).

${ }^{\mathrm{b}}$ Pretrial detention: The dataset decreased from 185,275 total cases to 109, 823 available cases because in 39 percent of cases this outcome was not applicable due to dismissal, diversion, or other forms of early disposition. Model 1 includes 108,450 out of 109,823 available cases because of missingness by race. The Heckman procedure to control for selection bias based on case rejection and dismissal was also performed but was omitted from the table because it did not change results and the correlation between error terms was not significantly different from $0\left(\chi^{2}(1)=2.41, p=.12\right)$. Dismissal: Model 1 includes 184,305 out of 
185,275 available cases because of missingness by race. Numbers decreased in Models 2 and 3 as additional controls introduced missingness. SES and defense counsel variables contributed to this change the most. Custodial Plea Offer: includes misdemeanors only. Model 1 contains 97,472 cases out of 98,557 available cases due to missingness by race. Incarceration Sentence: although there were 106,776 cases at this point, Model 1 includes 136,607 cases because the Heckman procedure used to run this model added cases that had been dismissed or diverted.

${ }^{*} p<.05 .{ }^{\dagger} p<.1$ (two-tailed test). Given the large sample size, most predictors were statistically significant at $p<.001$ level. 
Table 3. Racial Differences in Odds Ratios by Offense Type and Offense Category for Pretrial Detention, Dismissal, Custodial Plea, and Incarceration

\begin{tabular}{|c|c|c|c|c|c|c|}
\hline \multirow{2}{*}{$\begin{array}{l}\text { Offense } \\
\text { Type }\end{array}$} & \multirow{2}{*}{$\begin{array}{c}\text { Offense } \\
\text { Category }\end{array}$} & & $\begin{array}{c}\text { Pretrial } \\
\text { Detention }\end{array}$ & $\begin{array}{c}\text { Non- } \\
\text { Dismissal }\end{array}$ & $\begin{array}{c}\text { Custodial } \\
\text { Plea } \\
\text { Offer }\end{array}$ & $\begin{array}{c}\text { Incarceration } \\
\text { Sentence }\end{array}$ \\
\hline & & & \multicolumn{4}{|c|}{ Percent difference in odds vs. whites (direction of relation) } \\
\hline \multirow{6}{*}{ Person } & \multirow{3}{*}{ Felony } & Black & $40.9 \uparrow^{*}$ & $18.9 \downarrow$ & - & $31.9 \uparrow^{*}$ \\
\hline & & Latino & $20.9 \uparrow *$ & $32.7 \downarrow$ & - & $43.9 \uparrow$ \\
\hline & & Asian & $89.5 \downarrow *$ & $4.5 \downarrow$ & - & $93.3 \uparrow *$ \\
\hline & \multirow{3}{*}{ Misd. } & Black & $131.1 \uparrow *$ & $38.2 \downarrow^{*}$ & $187.8 \uparrow *$ & $89.3 \uparrow *$ \\
\hline & & Latino & $57.5 \uparrow *$ & $32.8 \downarrow^{*}$ & $47.2 \uparrow$ & $32.3 \uparrow$ \\
\hline & & Asian & $97.9 \downarrow *$ & $23.3 \downarrow *$ & $24.2 \downarrow$ & $51.8 \downarrow^{*}$ \\
\hline \multirow{6}{*}{ Property } & \multirow{3}{*}{ Felony } & Black & $34.5 \uparrow *$ & $33.4 \downarrow^{*}$ & - & $41.7 \uparrow *$ \\
\hline & & Latino & $8.5 \uparrow *$ & $10.3 \downarrow$ & - & $19.6 \uparrow *$ \\
\hline & & Asian & $106.2 \downarrow^{*}$ & $12.6 \downarrow$ & - & $186.1 \downarrow^{*}$ \\
\hline & \multirow{3}{*}{ Misd. } & Black & $37.3 \uparrow^{*}$ & $23.5 \downarrow^{*}$ & $75.9 \uparrow *$ & $9.2 \uparrow *$ \\
\hline & & Latino & $23.7 \uparrow *$ & $34.5 \downarrow^{*}$ & $28.5 \uparrow *$ & $0.2 \downarrow$ \\
\hline & & Asian & $403.4 \downarrow^{*}$ & $9.7 \uparrow *$ & $306.1 \downarrow *$ & $317.9 \downarrow^{*}$ \\
\hline \multirow{6}{*}{ Drug } & \multirow{3}{*}{ Felony } & Black & $54.8 \uparrow^{*}$ & $29.9 \downarrow$ & - & $80.1 \uparrow *$ \\
\hline & & Latino & $9.2 \uparrow$ & $36.3 \downarrow^{*}$ & - & $49.6 \uparrow *$ \\
\hline & & Asian & $19.9 \downarrow$ & $5.3 \uparrow$ & - & $18.1 \uparrow$ \\
\hline & \multirow{3}{*}{ Misd. } & Black & $72.1 \uparrow$ & $41.2 \uparrow *$ & $229.4 \uparrow *$ & $84.7 \uparrow *$ \\
\hline & & Latino & $15.6 \uparrow$ & $72.0 \uparrow *$ & $112.2 \uparrow *$ & $10.9 \uparrow$ \\
\hline & & Asian & $42.9 \downarrow$ & $33.2 \uparrow^{*}$ & $35.6 \downarrow$ & $92.4 \downarrow^{*}$ \\
\hline
\end{tabular}

NOTE: - (em dash) indicates entries that are not applicable.

$\uparrow$ indicates more punitive outcomes compared to whites, $\downarrow$ incites more lenient outcome. For consistency in the direction of punitiveness for all dependent variables, "dismissals" are reported as "non-dismissals".

$* p<.05$ (two-tailed test). 


\begin{tabular}{|c|c|c|c|c|c|c|c|c|c|c|c|}
\hline & & & Combination of Punitive Outcomes & 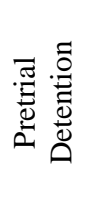 & 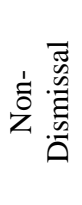 & 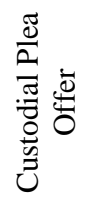 & 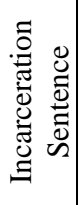 & White & Black & Latino & Asian \\
\hline \multirow{6}{*}{ 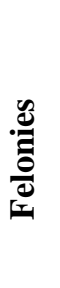 } & Most & A & Detained, not dismissed, incarcerated & 1 & 1 & - & 1 & 0.28 & 0.33 & 0.30 & 0.15 \\
\hline & disadvantaged & $\mathrm{B}$ & Not detained, not dismissed, incarcerated & 0 & 1 & - & 1 & 0.04 & 0.04 & 0.04 & 0.05 \\
\hline & & $\mathrm{C}$ & Detained, not dismissed, not incarcerated & 1 & 1 & - & 0 & 0.14 & 0.12 & 0.11 & 0.14 \\
\hline & $\sqrt{l}$ & $\mathrm{D}$ & Not detained, not dismissed, not incarcerated & 0 & 1 & - & 0 & 0.23 & 0.17 & 0.20 & 0.27 \\
\hline & Least & $\mathrm{E}$ & Detained, dismissed, not incarcerated & 1 & 0 & - & - & 0.12 & 0.15 & 0.13 & 0.08 \\
\hline & disadvantaged & $\mathrm{F}$ & Not detained, dismissed, not incarcerated & 0 & 0 & - & - & 0.18 & 0.18 & 0.20 & 0.22 \\
\hline \multirow{5}{*}{ 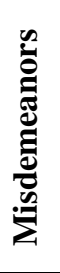 } & Most & G & Detained, not dismissed, custodial plea, incarcerated & 1 & 1 & 1 & 1 & 0.02 & 0.03 & 0.02 & 0.01 \\
\hline & disadvantaged & $\mathrm{H}$ & Not detained, not dismissed, custodial plea, incarcerated & 0 & 1 & 1 & 1 & 0.07 & 0.08 & 0.06 & 0.02 \\
\hline & & $\mathrm{I}$ & Not detained, not dismissed, custodial plea, not incarcerated & 0 & 1 & 1 & 0 & 0.07 & 0.09 & 0.07 & 0.03 \\
\hline & $\sqrt{3}$ & $\mathrm{~J}$ & Not detained, not dismissed, no custodial plea, not incarcerated & 0 & 1 & 0 & 0 & 0.56 & 0.49 & 0.52 & 0.60 \\
\hline & $\begin{array}{l}\text { Least } \\
\text { disadvantaged }\end{array}$ & $\mathrm{K}$ & Not detained, dismissed, no custodial plea, not incarcerated & 0 & 0 & 0 & - & 0.16 & 0.17 & 0.18 & 0.20 \\
\hline
\end{tabular}

NOTE: — (em dash) indicates entries that are not applicable.

Pretrial detention, 0 = released, $1=$ in custody; dismissal, $0=$ dismissed, $1=$ retained; custodial plea offer, $0=$ non-custodial, $1=$ jail/prison; incarceration sentence, $0=$ non-custodial, $1=$ jail/prison. Combinations which included dismissals cannot result in incarceration (though a plea offer can be made prior to dismissal). 


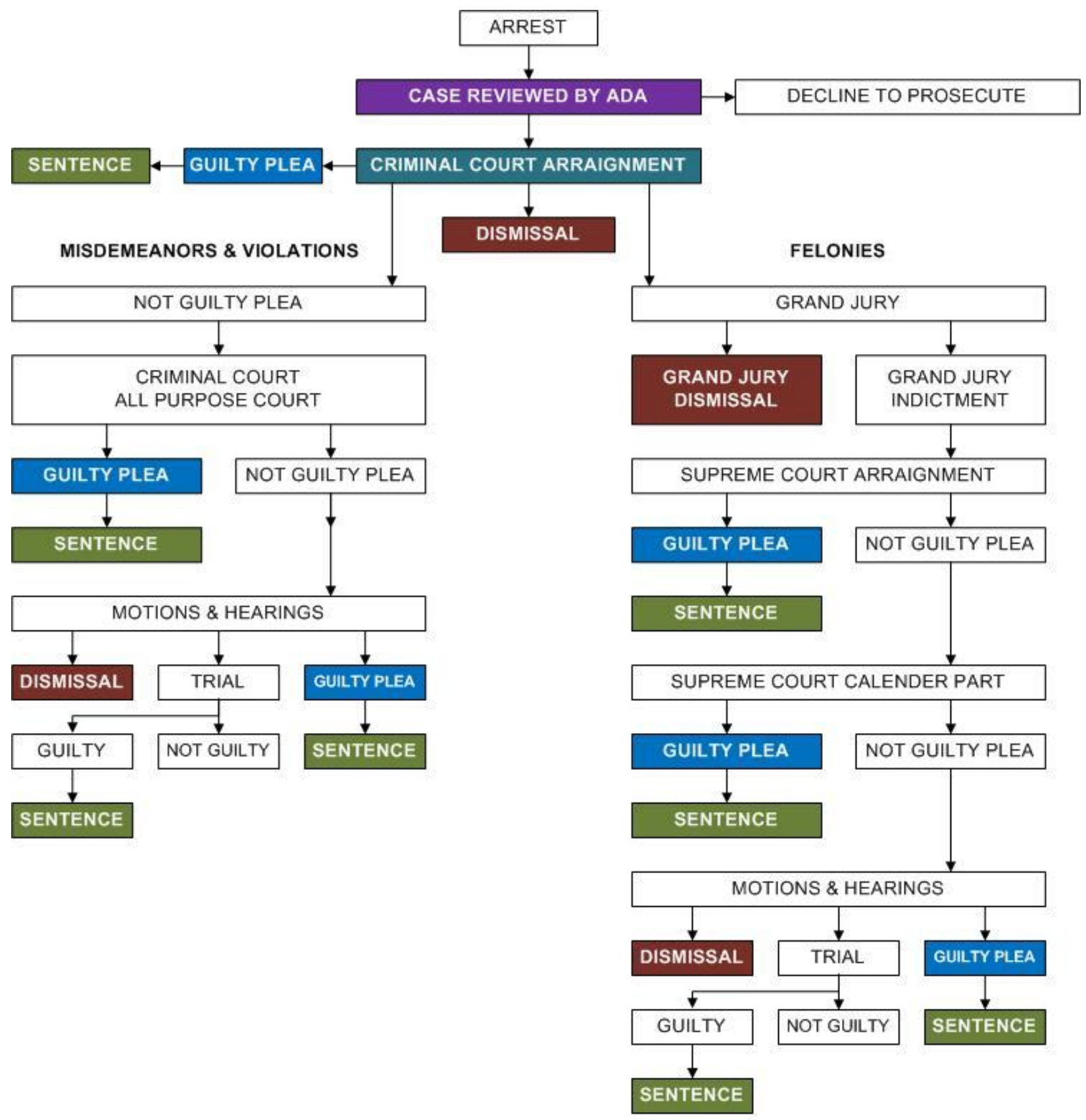


Online Appendix A: Odds Ratios Predicting Pretrial Detention, Dismissal, Custodial Pleas, and Incarceration (Restricted Samples based on the Number of Cases in Model 3)

\begin{tabular}{|c|c|c|c|c|c|c|c|c|c|c|c|c|}
\hline \multirow[b]{2}{*}{ Variables } & \multicolumn{3}{|c|}{ Pretrial Detention } & \multicolumn{3}{|c|}{ Dismissal } & \multicolumn{3}{|c|}{ Custodial Plea Offer } & \multicolumn{3}{|c|}{ Incarceration Sentence } \\
\hline & Model 1 & Model 2 & Model 3 & Model 1 & Model 2 & Model 3 & Model 1 & Model 2 & Model 3 & Model 1 & Model 2 & Model 3 \\
\hline Black & $2.433^{*}$ & $1.564^{*}$ & $1.478 *$ & $1.331 *$ & $1.448^{*}$ & $1.346^{*}$ & $3.027 *$ & $1.698 *$ & $1.666^{*}$ & $1.885^{*}$ & $1.224^{*}$ & $1.245^{*}$ \\
\hline Latino & $1.627^{*}$ & $1.177^{*}$ & $1.144 *$ & $1.558 *$ & $1.477^{*}$ & $1.345^{*}$ & $1.622 *$ & $1.215^{*}$ & $1.212^{*}$ & $1.281^{\dagger}$ & 0.989 & 1.014 \\
\hline Asian & $0.334 *$ & $0.436^{*}$ & $0.411 *$ & $1.360^{*}$ & $1.049 *$ & $1.084 *$ & $0.281 *$ & $0.353^{*}$ & $0.330^{*}$ & $0.327 *$ & $0.453 *$ & $0.441 *$ \\
\hline Other & 0.856 & 0.871 & 0.842 & $1.543^{*}$ & $1.267^{*}$ & $1.276^{*}$ & 0.931 & 0.914 & 0.920 & 0.764 & 0.912 & 0.921 \\
\hline Age & & $1.017 *$ & $1.018^{*}$ & & 0.997 & 0.998 & & $1.030 *$ & $1.030 *$ & & $1.013 *$ & $1.014 *$ \\
\hline Male & & $2.027 *$ & $2.018^{*}$ & & 0.974 & 0.992 & & $1.474 *$ & $1.427 *$ & & $1.458 *$ & $1.448 *$ \\
\hline Detained & & - & - & & $0.330 *$ & $0.331 *$ & & $1.111 *$ & $1.105^{*}$ & & $1.081 *$ & $1.078 *$ \\
\hline A misdemeanor & & $2.203^{*}$ & $2.171 *$ & & $1.227^{*}$ & $1.226^{*}$ & & $1.976^{*}$ & $1.966^{\dagger}$ & & $2.226^{*}$ & $2.233^{*}$ \\
\hline E felony & & $10.625^{*}$ & $10.44^{*}$ & & $1.652 *$ & $1.653 *$ & & - & - & & $7.562 *$ & $7.331 *$ \\
\hline D felony & & $10.431 *$ & $10.19 *$ & & $1.553 *$ & $1.570 *$ & & - & - & & $7.680 *$ & $7.396^{*}$ \\
\hline C felony & & $22.268 *$ & $22.80 *$ & & $2.571 *$ & $2.332 *$ & & - & - & & $13.94 *$ & $13.72 *$ \\
\hline B felony & & $21.010 *$ & $21.28 *$ & & $1.618^{*}$ & $1.507 *$ & & - & - & & $11.69 *$ & $11.44 *$ \\
\hline A felony & & $119.53 *$ & $165.4 *$ & & $1.416^{*}$ & $1.206^{*}$ & & - & - & & $37.95^{*}$ & $39.22 *$ \\
\hline Person crime & & $2.002 *$ & $2.004 *$ & & $3.488^{*}$ & $3.400 *$ & & $5.711 *$ & $5.473 *$ & & $1.903 *$ & $1.903 *$ \\
\hline Property crime & & $1.911 *$ & $1.824 *$ & & 1.051 & 1.097 & & $2.809 *$ & $2.743 *$ & & $1.721 *$ & $1.670 *$ \\
\hline Drug crime & & $2.050 *$ & $2.053 *$ & & 0.997 & 0.918 & & $3.809 *$ & $3.864 *$ & & $1.981 *$ & $2.016^{*}$ \\
\hline Charges & & $1.286^{*}$ & $1.290 *$ & & $0.854 *$ & $0.851 *$ & & 1.096 & 1.109 & & $1.384 *$ & $1.385^{*}$ \\
\hline Counts & & $1.016^{*}$ & $1.016^{*}$ & & 1.002 & 1.003 & & $1.100 *$ & $1.089 *$ & & $1.007 *$ & $1.006^{*}$ \\
\hline Prior arrest & & $3.844^{*}$ & $3.815^{*}$ & & $1.391 *$ & $1.354 *$ & & $5.798 *$ & $5.769 *$ & & $3.320 *$ & $3.340 *$ \\
\hline Prior prison & & $3.543^{*}$ & $3.505^{*}$ & & $1.086^{*}$ & $1.077 *$ & & $4.466^{*}$ & $4.460^{*}$ & & $2.419 *$ & $2.415^{*}$ \\
\hline Legal aid & & & $2.408^{*}$ & & & $0.823^{*}$ & & & $2.042 *$ & & & $1.249 *$ \\
\hline $18(b)^{a}$ & & & $3.110 *$ & & & $1.292 *$ & & & $3.325^{*}$ & & & $1.611^{*}$ \\
\hline NYCDS & & & $2.866^{*}$ & & & $0.821 *$ & & & $2.938^{*}$ & & & $1.435^{*}$ \\
\hline NDS & & & $2.118^{*}$ & & & 1.136 & & & $1.551 *$ & & & $1.131 *$ \\
\hline Harlem & & & $0.916^{*}$ & & & $1.088^{*}$ & & & 0.996 & & & $0.976^{*}$ \\
\hline MTDT -West & & & $1.102 *$ & & & $0.787^{*}$ & & & $1.189 *$ & & & $1.155^{*}$ \\
\hline MTDT -East & & & $1.100 *$ & & & $0.877^{*}$ & & & 1.028 & & & $1.073^{*}$ \\
\hline Outside NYC & & & 1.066 & & & $0.776^{*}$ & & & $1.101 *$ & & & $1.244 *$ \\
\hline Constant & $0.205^{*}$ & $0.004 *$ & $0.002 *$ & $0.197 *$ & $0.393 *$ & $0.498^{*}$ & $0.298 *$ & $0.005^{*}$ & $0.002 *$ & $0.294 *$ & $0.006^{*}$ & $0.006^{*}$ \\
\hline
\end{tabular}




\begin{tabular}{|c|c|c|c|c|c|c|c|c|c|c|c|c|}
\hline \multirow[b]{2}{*}{ Variables } & \multicolumn{3}{|c|}{ Pretrial Detention } & \multicolumn{3}{|c|}{ Dismissal } & \multicolumn{3}{|c|}{ Custodial Plea Offer } & \multicolumn{3}{|c|}{ Incarceration Sentence } \\
\hline & Model 1 & Model 2 & Model 3 & Model 1 & Model 2 & Model 3 & Model 1 & Model 2 & Model 3 & Model 1 & Model 2 & Model 3 \\
\hline Pseudo $R^{2}$ & 0.027 & 0.285 & 0.292 & 0.003 & 0.261 & 0.266 & 0.046 & 0.297 & 0.303 & 0.019 & 0.189 & 0.191 \\
\hline$-2 L L$ & 113,523 & 83,417 & 82,676 & 169,246 & 125,451 & 124,555 & 117,979 & 86,875 & 86,156 & 120,222 & 99,419 & 99,171 \\
\hline & 100,510 & 100,510 & 100,510 & 164,748 & 164,748 & 164,748 & 93,558 & 93,558 & 93,558 & 100,035 & 100,035 & 100,035 \\
\hline
\end{tabular}


Online Appendix B. Unstandardized Coefficients (Robust Standard Errors) for Models Predicting Pretrial Detention, Dismissal, Custodial Pleas, and Incarceration

\begin{tabular}{|c|c|c|c|c|c|c|c|c|c|c|c|c|}
\hline \multirow[b]{2}{*}{ Variables } & \multicolumn{3}{|c|}{ Pretrial Detention } & \multicolumn{3}{|c|}{ Dismissal } & \multicolumn{3}{|c|}{ Custodial Plea Offer } & \multicolumn{3}{|c|}{ Incarceration Sentence } \\
\hline & Model 1 & Model 2 & Model 3 & Model 1 & Model 2 & Model 3 & Model 1 & Model 2 & Model 3 & Model 1 & Model 2 & Model 3 \\
\hline \multirow[t]{2}{*}{ Black } & 0.87 & 0.44 & 0.39 & 0.13 & 0.36 & 0.30 & 1.11 & 0.53 & 0.51 & 0.58 & 0.24 & 0.26 \\
\hline & $(0.04)$ & $(0.05)$ & $(0.03)$ & $(0.08)$ & $(0.07)$ & $(0.06)$ & $(0.08)$ & $(0.07)$ & $(0.05)$ & $(0.02)$ & $(0.03)$ & $(0.03)$ \\
\hline \multirow[t]{2}{*}{ Latino } & 0.48 & 0.15 & 0.13 & 0.33 & 0.40 & 0.30 & 0.48 & 0.19 & 0.19 & 0.42 & 0.01 & 0.03 \\
\hline & $(0.10)$ & $(0.06)$ & $(0.04)$ & $(0.10)$ & $(0.07)$ & $(0.06)$ & $(0.18)$ & $(0.09)$ & $(0.08)$ & $(0.01)$ & $(0.05)$ & $(0.04)$ \\
\hline \multirow[t]{2}{*}{ Asian } & -1.07 & -0.79 & -0.89 & 0.15 & 0.01 & 0.08 & -1.24 & -1.04 & -1.11 & -0.31 & -0.69 & -0.71 \\
\hline & $(0.03)$ & $(0.01)$ & $(0.01)$ & $(0.02)$ & $(0.03)$ & $(0.02)$ & $(0.08)$ & $(0.05)$ & $(0.05)$ & $(0.01)$ & $(0.03)$ & $(0.03)$ \\
\hline \multirow[t]{2}{*}{ Other } & -0.19 & -0.24 & -0.17 & 0.42 & 0.39 & 0.24 & -0.05 & -0.09 & -0.08 & 0.21 & -0.11 & -0.13 \\
\hline & $(0.14)$ & $(0.19)$ & $(0.19)$ & $(0.07)$ & $(0.07)$ & $(0.02)$ & $(0.44)$ & $(0.34)$ & $(0.35)$ & $(0.10)$ & $(0.15)$ & $(0.19)$ \\
\hline \multirow[t]{2}{*}{ Age } & & 0.01 & 0.02 & & 0.00 & 0.00 & & 0.03 & 0.03 & & 0.02 & 0.02 \\
\hline & & $(0.00)$ & $(0.00)$ & & $(0.00)$ & $(0.00)$ & & $(0.00)$ & $(0.00)$ & & $(0.00)$ & $(0.00)$ \\
\hline \multirow{2}{*}{ Male } & & 0.69 & 0.70 & & 0.01 & -0.01 & & 0.39 & 0.36 & & 0.41 & 0.41 \\
\hline & & $(0.08)$ & $(0.07)$ & & $(0.04)$ & $(0.04)$ & & $(0.03)$ & $(0.04)$ & & $(0.08)$ & $(0.08)$ \\
\hline \multirow[t]{2}{*}{ Detained } & & - & - & & -1.11 & -1.10 & & 0.11 & 0.10 & & 0.05 & 0.04 \\
\hline & & & & & $(0.01)$ & $(0.01)$ & & $(0.01)$ & $(0.01)$ & & $(0.01)$ & $(0.01)$ \\
\hline \multirow[t]{2}{*}{ A misdemeanor } & & 0.81 & 0.78 & & 0.22 & 0.20 & & 0.69 & 0.68 & & 0.93 & 0.92 \\
\hline & & $(0.29)$ & $(0.30)$ & & (0.09) & $(0.06)$ & & $(0.32)$ & $(0.31)$ & & $(0.18)$ & $(0.18)$ \\
\hline \multirow[t]{2}{*}{ E felony } & & 2.33 & 2.35 & & 0.65 & 0.50 & & - & - & & 2.24 & 2.23 \\
\hline & & $(0.30)$ & $(0.30)$ & & $(0.06)$ & $(0.05)$ & & & & & $(0.20)$ & $(0.21)$ \\
\hline \multirow[t]{2}{*}{ D felony } & & 2.31 & 2.32 & & 0.62 & 0.45 & & - & - & & 2.24 & 2.21 \\
\hline & & $(0.29)$ & $(0.30)$ & & $(0.07)$ & $(0.04)$ & & & & & $(0.20)$ & $(0.20)$ \\
\hline \multirow[t]{2}{*}{ C felony } & & 3.07 & 3.13 & & 1.04 & 0.85 & & - & - & & 2.81 & 2.83 \\
\hline & & $(0.36)$ & $(0.34)$ & & $(0.06)$ & $(0.04)$ & & & & & $(0.26)$ & $(0.26)$ \\
\hline \multirow[t]{2}{*}{ B felony } & & 3.06 & 3.06 & & 0.62 & 0.41 & & - & - & & 2.67 & 2.66 \\
\hline & & $(0.24)$ & $(0.23)$ & & $(0.04)$ & $(0.06)$ & & & & & $(0.16)$ & $(0.17)$ \\
\hline \multirow[t]{2}{*}{ A felony } & & 4.77 & 5.11 & & 0.37 & 0.19 & & - & - & & 3.74 & 3.74 \\
\hline & & $(0.26)$ & $(0.21)$ & & $(0.11)$ & $(0.08)$ & & & & & $(0.07)$ & $(0.07)$ \\
\hline \multirow{2}{*}{ Property crime } & & 0.62 & 0.60 & & 0.10 & 0.09 & & 1.03 & 1.01 & & 0.31 & 0.34 \\
\hline & & $(0.03)$ & $(0.02)$ & & $(0.14)$ & $(0.15)$ & & $(0.10)$ & $(0.11)$ & & $(0.04)$ & $(0.04)$ \\
\hline \multirow[t]{2}{*}{ Person crime } & & 0.69 & 0.70 & & 1.25 & 1.22 & & 1.73 & 1.70 & & 0.40 & 0.37 \\
\hline & & $(0.04)$ & $(0.05)$ & & $(0.11)$ & $(0.11)$ & & $(0.25)$ & $(0.24)$ & & $(0.03)$ & $(0.05)$ \\
\hline \multirow[t]{2}{*}{ Drug crime } & & 0.68 & 0.72 & & 0.04 & -0.09 & & 1.34 & 1.35 & & 0.58 & 0.60 \\
\hline & & $(0.08)$ & $(0.07)$ & & $(0.07)$ & $(0.08)$ & & $(0.20)$ & $(0.17)$ & & $(0.10)$ & $(0.08)$ \\
\hline \multirow[t]{2}{*}{ Charges } & & 0.24 & 0.25 & & -0.14 & -0.16 & & 0.09 & 0.10 & & 0.36 & 0.36 \\
\hline & & $(0.04)$ & $(0.05)$ & & $(0.01)$ & $(0.01)$ & & $(0.05)$ & $(0.05)$ & & $(0.01)$ & $(0.01)$ \\
\hline
\end{tabular}




\begin{tabular}{|c|c|c|c|c|c|c|c|c|c|c|c|c|}
\hline \multirow[b]{2}{*}{ Variables } & \multicolumn{3}{|c|}{ Pretrial Detention } & \multicolumn{3}{|c|}{ Dismissal } & \multicolumn{3}{|c|}{ Custodial Plea Offer } & \multicolumn{3}{|c|}{ Incarceration Sentence } \\
\hline & Model 1 & Model 2 & Model 3 & Model 1 & Model 2 & Model 3 & Model 1 & Model 2 & Model 3 & Model 1 & Model 2 & Model 3 \\
\hline \multirow[t]{2}{*}{ Counts } & & 0.02 & 0.02 & & 0.00 & 0.00 & & 0.09 & 0.09 & & 0.01 & 0.01 \\
\hline & & $(0.01)$ & $(0.01)$ & & $(0.00)$ & $(0.00)$ & & $(0.03)$ & $(0.03)$ & & $(0.00)$ & $(0.00)$ \\
\hline \multirow{2}{*}{ Prior arrest } & & 1.35 & 1.34 & & 0.27 & 0.30 & & 1.74 & 1.75 & & 1.38 & 1.40 \\
\hline & & $(0.11)$ & $(0.11)$ & & $(0.00)$ & $(0.00)$ & & $(0.12)$ & $(0.12)$ & & $(0.08)$ & $(0.08)$ \\
\hline \multirow[t]{2}{*}{ Prior prison } & & 1.29 & 1.25 & & 0.02 & 0.07 & & 1.50 & 1.50 & & 1.04 & 1.02 \\
\hline & & $(0.11)$ & $(0.11)$ & & $(0.01)$ & $(0.02)$ & & $(0.11)$ & $(0.11)$ & & $(0.05)$ & $0.05)$ \\
\hline \multirow[t]{2}{*}{ Legal aid } & & & 0.88 & & & -0.20 & & & 0.71 & & & 0.24 \\
\hline & & & $(0.10)$ & & & $(0.09)$ & & & $(0.17)$ & & & $(0.03)$ \\
\hline \multirow[t]{2}{*}{$18(b)^{a}$} & & & 1.13 & & & 0.26 & & & 1.20 & & & 0.44 \\
\hline & & & $(0.18)$ & & & $(0.04)$ & & & $(0.17)$ & & & $(0.02)$ \\
\hline \multirow{2}{*}{ NYCDS } & & & 1.05 & & & -0.20 & & & 1.08 & & & 0.42 \\
\hline & & & $(0.13)$ & & & $(0.07)$ & & & $(0.10)$ & & & $(0.03)$ \\
\hline \multirow[t]{2}{*}{ NDS } & & & 0.75 & & & 0.13 & & & 0.44 & & & 0.13 \\
\hline & & & $(0.12)$ & & & $(0.10)$ & & & $(0.12)$ & & & $(0.03)$ \\
\hline \multirow[t]{2}{*}{ Harlem } & & & -0.09 & & & 0.08 & & & 0.00 & & & 0.00 \\
\hline & & & $(0.01)$ & & & $(0.01)$ & & & $(0.01)$ & & & $(0.00)$ \\
\hline \multirow[t]{2}{*}{ MTDT -West } & & & 0.10 & & & -0.24 & & & 0.17 & & & 0.17 \\
\hline & & & $(0.03)$ & & & $(0.01)$ & & & $(0.02)$ & & & $(0.01)$ \\
\hline \multirow[t]{2}{*}{ MTDT -East } & & & 0.10 & & & -0.13 & & & 0.03 & & & 0.10 \\
\hline & & & $(0.03)$ & & & $(0.01)$ & & & $(0.02)$ & & & $(0.01)$ \\
\hline Outside NYC & & & $\begin{array}{r}0.06 \\
(0.04)\end{array}$ & & & $\begin{array}{r}-0.25 \\
(0.01)\end{array}$ & & & $\begin{array}{r}0.10 \\
(0.04)\end{array}$ & & & $\begin{array}{r}0.27 \\
(0.02) \\
\end{array}$ \\
\hline Constant & $\begin{array}{r}-1.60 \\
(0.05)\end{array}$ & $\begin{array}{r}-5.51 \\
(0.10)\end{array}$ & $\begin{array}{r}-6.44 \\
(0.16)\end{array}$ & $\begin{array}{r}-1.30 \\
(0.05)\end{array}$ & $\begin{array}{r}-1.13 \\
(0.05)\end{array}$ & $\begin{array}{r}-0.70 \\
(0.05)\end{array}$ & $\begin{array}{r}-1.25 \\
(0.12)\end{array}$ & $\begin{array}{r}-5.40 \\
(0.26)\end{array}$ & $\begin{array}{r}-6.19 \\
(0.25)\end{array}$ & $\begin{array}{r}-0.78 \\
(0.03)\end{array}$ & $\begin{array}{r}-5.65 \\
(0.11)\end{array}$ & $\begin{array}{c}-5.98 \\
(0.10)\end{array}$ \\
\hline Nagelkerke $R^{2}$ & .043 & .402 & .418 & .004 & .367 & .373 & .079 & .441 & .450 & .030 & .288 & .295 \\
\hline$-2 L L$ & 121,566 & 89,828 & 82,676 & 205,417 & 136,617 & 124,555 & 121,902 & 88,371 & 86,156 & 328,096 & 104,786 & 99,171 \\
\hline$N^{\mathrm{b}}$ & 108,450 & 108,280 & 100,510 & 184,305 & 176,108 & 164,748 & 97,472 & 95,113 & 93,588 & 136,607 & 136,604 & 128,909 \\
\hline
\end{tabular}


Online Appendix C. Adding Prior Bench Warrants to Models Predicting Pretrial Detention (Prior Arrest Excluded)

\begin{tabular}{|c|c|c|c|c|c|c|}
\hline \multirow[b]{3}{*}{ Variables } & \multicolumn{6}{|c|}{ Pretrial Detention } \\
\hline & \multicolumn{3}{|c|}{ Model 1: Race, Controls, No SES } & \multicolumn{3}{|c|}{ Model 2: Race, Controls, With SES } \\
\hline & Coefficient & $\begin{array}{c}\text { Robust Standard } \\
\text { Error }\end{array}$ & Odds Ratio & Coefficient & $\begin{array}{c}\text { Robust Standard } \\
\text { Error }\end{array}$ & Odds Ratio \\
\hline Black & 0.592 & 0.045 & $1.807^{*}$ & 0.520 & 0.026 & $1.681^{*}$ \\
\hline Latino & 0.292 & 0.067 & $1.340^{*}$ & 0.249 & 0.052 & $1.283^{*}$ \\
\hline Asian & -0.761 & 0.034 & $0.467 *$ & -0.853 & 0.022 & $0.426^{*}$ \\
\hline Other & -0.164 & 0.199 & 0.849 & -0.098 & 0.204 & 0.907 \\
\hline Age & 0.011 & 0.002 & $1.011 *$ & 0.015 & 0.002 & $1.015^{*}$ \\
\hline Male & 0.775 & 0.066 & $2.170 *$ & 0.786 & 0.064 & $2.195 *$ \\
\hline A misdemeanor & 0.719 & 0.300 & $2.052 *$ & 0.689 & 0.304 & $1.991 *$ \\
\hline E felony & 2.280 & 0.317 & $9.774 *$ & 2.322 & 0.320 & $10.198 *$ \\
\hline D felony & 2.265 & 0.294 & $9.629 *$ & 2.303 & 0.300 & $10.009 *$ \\
\hline C felony & 3.004 & 0.390 & $20.169 *$ & 3.070 & 0.366 & $21.550^{*}$ \\
\hline B felony & 2.967 & 0.260 & $19.425 *$ & 2.976 & 0.251 & $19.618 *$ \\
\hline A felony & 4.492 & 0.302 & $89.267^{*}$ & 4.838 & 0.229 & $126.193 *$ \\
\hline Property crime & 0.817 & 0.062 & $2.264 *$ & 0.815 & 0.056 & $2.259 *$ \\
\hline Person crime & 0.876 & 0.073 & $2.402 *$ & 0.876 & 0.080 & $2.402 *$ \\
\hline Drug crime & 0.923 & 0.036 & $2.517 *$ & 0.946 & 0.031 & $2.577 *$ \\
\hline Charges & 0.247 & 0.047 & $1.280^{*}$ & 0.263 & 0.049 & $1.300 *$ \\
\hline Counts & 0.018 & 0.009 & $1.018 *$ & 0.018 & 0.008 & $1.018 *$ \\
\hline Prior bench warrants & 1.289 & 0.075 & $3.630 *$ & 1.265 & 0.064 & $3.542 *$ \\
\hline Prior prison & 1.255 & 0.135 & $3.506^{*}$ & 1.209 & 0.134 & $3.350 *$ \\
\hline Legal aid & & & & 0.894 & 0.116 & $2.444 *$ \\
\hline $18(b)^{a}$ & & & & 1.155 & 0.180 & $3.173 *$ \\
\hline NYCDS & & & & 1.093 & 0.136 & $2.984 *$ \\
\hline NDS & & & & 0.822 & 0.153 & $2.275 *$ \\
\hline Harlem & & & & -0.076 & 0.004 & $0.927 *$ \\
\hline MTDT -West & & & & 0.017 & 0.022 & 1.017 \\
\hline MTDT -East & & & & 0.060 & 0.022 & $1.061 *$ \\
\hline Outside NYC & & & & -0.032 & 0.028 & 0.968 \\
\hline Constant & -5.339 & 0.092 & $0.005^{*}$ & -6.282 & 0.173 & $0.002 *$ \\
\hline
\end{tabular}




\begin{tabular}{|c|c|c|c|c|c|c|}
\hline \multirow[b]{3}{*}{ Variables } & \multicolumn{6}{|c|}{ Pretrial Detention } \\
\hline & \multicolumn{3}{|c|}{ Model 1: Race, Controls, No SES } & \multicolumn{3}{|c|}{ Model 2: Race, Controls, With SES } \\
\hline & Coefficient & $\begin{array}{c}\text { Robust Standard } \\
\text { Error }\end{array}$ & Odds Ratio & Coefficient & $\begin{array}{c}\text { Robust Standard } \\
\text { Error }\end{array}$ & Odds Ratio \\
\hline Nagelkerke $R^{2}$ & .394 & & & .411 & & \\
\hline$-2 L L$ & 90,634 & & & 83,368 & & \\
\hline$N^{\mathrm{b}}$ & 108,280 & & & 100,510 & & \\
\hline
\end{tabular}

